\title{
Carbon Source-Dependent Effects of Anaerobic Soil Disinfestation on Soil Microbiome and Suppression of Rhizoctonia solani AG-5 and Pratylenchus penetrans
}

\author{
Shashika S. Hewavitharana and Mark Mazzola
}

First author: Department of Plant Pathology, Washington State University, 1100 N. Western Ave., Wenatchee 98801; and second author: United States Department of Agriculture-Agricultural Research Service Tree Fruit Research Lab, 1104 N. Western Ave., Wenatchee, WA 98801. Accepted for publication 2 May 2016.

\begin{abstract}
Hewavitharana, S. S., and Mazzola, M. 2016. Carbon source-dependent effects of anaerobic soil disinfestation on soil microbiome and suppression of Rhizoctonia solani AG-5 and Pratylenchus penetrans. Phytopathology 106:1015-1028.

The effect of carbon source on efficacy of anaerobic soil disinfestation (ASD) toward suppression of apple root infection by Rhizoctonia solani AG-5 and Pratylenchus penetrans was examined. Orchard grass (GR), rice bran (RB), ethanol (ET), composted steer manure (CM), and Brassica juncea seed meal (SM) were used as ASD carbon inputs, with plant assays conducted in natural and pasteurized orchard soils. Subsequent studies investigated the effect of GR application rate used in ASD on control of these pathogens. In general, apple root infection by $R$. solani AG-5 was significantly lower in ET, GR, RB, and SM ASD treatments compared with the control. Among different ASD treatments, apple seedling growth was significantly greater when GR or SM was used as the

amendment type, compared with the control. In independent experiments, ASD-GR was consistently superior to ASD-CM for limiting pathogen activity in soils. ASD treatment with a grass input rate of $20 \mathrm{t} \mathrm{ha}^{-1}$ provided superior suppression of $P$. penetrans but grass application rate did not affect ASD efficacy in control of $R$. solani AG-5. The soil microbiome from ASD-GR-treated soils was clearly distinct from the control and ASD-CM-treated soils. In contrast, composition of the microbiome from control and ASD-CM-treated soils could not be differentiated. Comparative results from pasteurized and nonpasteurized soils suggest that there is potential for GR based ASD treatment to recruit microbial elements that persist over the anaerobic phase of soil incubation, which may functionally contribute to disease suppression. When ASD was conducted with GR, microbial diversity was markedly reduced relative to the control or ASD-CM soil suggesting that this parameter, typically associated with system resilience, was not instrumental to the function of ASD-induced soil suppressiveness.
\end{abstract} carbon input relative to all other ASD treatments. $R$. solani AG-5 DNA abundance was significantly reduced in all ASD treatments, regardless of

Apple replant disease (ARD) etiology in Washington State is incited by multiple species within the genera Ilyonectria (=Cylindrocarpon), Phytophthora, Pythium, and Rhizoctonia, and at times in concert with the lesion nematode Pratylenchus penetrans (Mazzola 1998). Rhizoctonia spp. and $P$. penetrans are significant pathogens in numerous crop production systems. In apple, members of the genus Rhizoctonia cause significant mortality in nursery environments (Burr et al. 1978), while numerous species and anastomosis groups (AG) are recognized as components of the ARD causal pathogen complex (Mazzola 1998). Rhizoctonia solani AG-5 and AG-6 caused the most damage to apple when evaluated in plant bioassays and are the most commonly encountered AG root pathogens of apple in the primary production region of north-central Washington State (Mazzola 1997).

Preplant soil fumigation is commonly utilized for control of soilborne pathogens, including Rhizoctonia spp. and Pratylenchus spp., when reestablishing apple orchards and nurseries on sites previously cultivated to this crop (Mai and Abawi 1981). Although broad-spectrum fumigant chemistries such as methyl bromide and 1,3-dichloropropene/chloropicrin have yielded effective ARD control, potential drawbacks of fumigation are significant (Mazzola and Manici 2012). The global phase-out of methyl bromide as part of the Montreal Protocol (UNEP 1987) and geographical restrictions

Corresponding author: M. Mazzola; E-mail address: mark.mazzola@ars.usda.gov

http://dx.doi.org/10.1094/PHYTO-12-15-0329-R

This article is in the public domain and not copyrightable. It may be freely reprinted with customary crediting of the source. The American Phytopathological Society, 2016.
Additional keywords: replant disease. on the use of certain fumigants such as 1,3-dicholoropropene (Helliker 2002) have resulted in increased interest in development of alternative preplant soilborne disease control methods in perennial production systems such as apple. Additionally, alternative replant disease control strategies are essential to support the increase in organic apple production (Granatstein and Dauer 2000) and greater rate of orchard renewal due to the introduction of new apple varieties.

A diversity of tactics has been explored for the control of diseases incited by Rhizoctonia and Pratylenchus spp. in orchard systems, including cultural control, utilization of tolerant rootstocks, and chemical control (Forge et al. 2013; Mazzola and Mullinix 2005; Mazzola et al. 2015; St. Laurent et al. 2008). Certain apple rootstocks released from the United States Department of AgricultureAgricultural Research Service (USDA-ARS) breeding program at Geneva, NY have possessed a higher level of tolerance to $P$. penetrans than the commercially established Malling series rootstocks (Isutsa and Merwin 2000; Mazzola et al. 2009); however, resistance to other ARD pathogens such as $R$. solani has not been assessed.

Anaerobic soil disinfestation (ASD) has demonstrated efficacy in the control of a wide range of soilborne plant pathogens in both controlled environment and field settings (Blok et al. 2000; Butler et al. 2012a; Momma et al. 2010). ASD is characteristically implemented through the addition of easily degradable organic matter and inundation with water, followed by tarping of the treated area with an oxygen-impermeable plastic cover. A large survey of published results indicated that the type of organic matter, or carbon input, did not affect the success of organic amendment applications 
under anaerobic conditions for reduction of several fungal soilborne pathogens (Bonanomi et al. 2007). However, for some pathogens, the efficacy of ASD may be related to the carbon input because both $S$ clerotium rolfsii and $R$. solani showed variable degrees in reduction based on the type of organic amendment (Butler et al. 2012b; McCarty II et al. 2014). Similarly, the type of carbon input, and the resulting unique volatile profile, influenced the capacity of ASD to control elements of the pathogen complex that incites apple replant disease (Hewavitharana et al. 2014).

The feasibility of ASD as a disease control option for orchardists will be dependent upon efficacy, carbon input availability, and associated costs, including the organic amendment, transportation, and field application. Minimizing quantity of the organic input can reduce application costs and may also lessen the treatment time by shortening the required aeration period following ASD to alleviate possible phytotoxicity. If a majority of the organic input can be supplied from the orchard itself, a significant positive impact on profitability may be realized. The goal of this study was to determine the effect of carbon source input type and application rate on the capacity of ASD to control ARD pathogens, and to infer the possible mechanisms of disease suppression by profiling the resident soil microbiome upon ASD treatment.

\section{MATERIALS AND METHODS}

Orchard soils. Pathogen susceptibility tests for $R$. solani AG-5 and $P$. penetrans were conducted using soils from different orchards due to the differential pathogen profiles resident to the sites. Soils used in this study were obtained from a conventionally managed commercial orchard (GC) located near Manson, WA (latitude $47^{\circ} 53^{\prime} 05^{\prime \prime} \mathrm{N}$, longitude $120^{\circ} 09^{\prime} 30^{\prime \prime} \mathrm{W}$ ) and the Washington State University Sunrise (SR) Research Orchard (Rock Island, WA; latitude $47^{\circ} 31^{\prime} 97^{\prime \prime} \mathrm{N}$, longitude $\left.120^{\circ} 07^{\prime} 30^{\prime \prime} \mathrm{W}\right)$. The GC orchard was established in 1991 on orchard ground previously planted to apple and was not fumigated prior to replanting 'Golden Delicious' on M7 rootstock. The dominant soil type at the GC orchard is Chelan gravelly sandy loam whereas the dominant soil type at the SR site is a Pogue fine sandy loam (Mazzola 1998). GC soil possessed a pH of 6 and organic matter content of 3.2\%, while SR soil had a pH of 6.9 and organic matter content of $1.2 \%$. The apple replant disease pathogen complex at GC orchard is composed of Cylindrocarpon destructans, various species of Pythium, and $R$. solani AG-5 acting in concert with $P$. penetrans (Mazzola 1998). GC soil was chosen for use in studies of ASD for the control of $R$. solani AG-5 due to its possessing low basal inoculum of this fungal pathogen. The low basal inoculum level facilitates the ability to understand the effect of soil treatments on the known level of artificial inoculum. The ARD pathogen complex in SR orchard soil is dominated by Pythium ultimum, P. sylvaticum, multinucleate Rhizoctonia spp. Cylindrocarpon spp., and Pratylenchus penetrans (Mazzola et al. 2015). SR soil was used in the study of ASD for the control of $P$. penetrans because this soil was previously reported to possess a high density of $P$. penetrans (Mazzola et al. 2015). Soil possessing a high basal density of $P$. penetrans was required because the inoculum level was naturally elevated by planting the susceptible host to create stringent test conditions. Soils were collected from the root zone of established trees at a soil depth of 10 to $30 \mathrm{~cm}$ during summer and autumn 2012. Soils were placed in 20-liter closed containers and transported to the USDA-ARS Tree Fruit Research Laboratory in Wenatchee, WA. Soils from the root zone of different trees were mixed in a 16-liter closed bin; large roots were removed by hand and soil was well mixed in a cement mixer (Kobalt, Mooresville, NC) for 3 to 5 min prior to use to obtain a representative sample from the orchard.

Carbon inputs used during ASD. The carbon input experiment was conducted in GC orchard soil. Five ASD carbon input types were used in this study: rice bran (RB), Brassica juncea 'Pacific Gold' seed meal (SM), composted steer manure (CM), 10\% ethanol (ET), and orchard grass residues (GR; freshly cut orchard grass clippings). Powdered RB was added to soil at a rate of 4.4 $\mathrm{t} \mathrm{ha}^{-1}$, with estimated nutrient concentrations of $\mathrm{C}=47.8 \%, \mathrm{~N}=$ $2.49 \%, \mathrm{P}=1.53 \%, \mathrm{~K}=1.60 \%, \mathrm{~S}=0.18 \%, \mathrm{C}: \mathrm{N}$ ration 19.1 , and $\mathrm{pH}=$ 6.2 (Soiltest Farm Consultants, Inc., Moses Lake, WA). B. juncea $\mathrm{SM}$ was applied to GC orchard soil at a rate of $4.4 \mathrm{tha}^{-1}$. This SM possessed a glucosinolate content of $178 \mu \mathrm{mol} \mathrm{g}^{-1}$ (Handiseni et al. 2013) and estimated nutrient concentrations of $\mathrm{C}=54.9 \%, \mathrm{~N}=$ $3.48 \%, \mathrm{P}=0.59 \%, \mathrm{~K}=0.70 \%, \mathrm{~S}=0.93 \%, \mathrm{C}: \mathrm{N}$ ratio 16.1 , and $\mathrm{pH}=$ 5.1 (Soiltest Farm Consultants, Inc.). The SM was passed through a 1 -mm standard sieve to obtain particles with a diameter $<1 \mathrm{~mm}$. CM was used in experiments at the rate of $10 \mathrm{t} \mathrm{ha}^{-1}$. CM consisted of $30 \%$ steer manure and $70 \%$ composted peat and forest products with total $\mathrm{C}, \mathrm{N}, \mathrm{P}, \mathrm{K}$, and $\mathrm{S}$ of $14.7,1.35,0.72,2.20$, and $0.45 \%$, respectively; a $\mathrm{C}: \mathrm{N}$ ratio of 11:1; and $\mathrm{pH} 8.4$ (Soiltest Farm Consultants, Inc.). Before use, CM was passed through a 1-mm standard sieve to obtain particles $<1 \mathrm{~mm}$. ET (ACS/USP-grade ethyl alcohol, 200 proof; Pharmco-Aaper, Brookfield, CT) was diluted to $10 \%$ concentration using distilled water. GR (Dactylis glomerata L.) was obtained from the Columbia View Experimental (CV) orchard located 12 miles north of East Wenatchee, WA. GR was applied to soil at a rate of $20 \mathrm{tha}^{-1}$ in experiments that examined the effect of different ASD carbon inputs on disease control efficacy. GR possessed a C:N ratio of $19: 1, \mathrm{pH}=6.3$ and total $\mathrm{C}, \mathrm{N}, \mathrm{P}, \mathrm{K}$, and $\mathrm{S}$ of $42.3,2.19,0.24,1.73$, and $0.18 \%$, respectively. Prior to use, GR were air dried overnight at room temperature and stored in the cold room in black polyethylene bags until use. To determine the optimal rates of GR input for control of $R$. solani AG-5 and P. penetrans, GR was added to GC and SR soil at rates of $5 \mathrm{t} \mathrm{ha}^{-1}$ (5GR), $10 \mathrm{t} \mathrm{ha}^{-1}$ (10GR), and $20 \mathrm{t} \mathrm{ha}^{-1}$ (20GR).

Preparation of $\boldsymbol{R}$. solani AG-5 inoculum. Inoculum of $R$. solani AG-5 was prepared on whole oat grains, as previously described (Mazzola 1997). After complete colonization of the oat grain substrate by the fungus, the inoculum was air dried overnight under a laminar flow hood. The inoculum was then ground to coarse particles of 2 to $3 \mathrm{~mm}$ using a blender (Magic Bullet; Homeland Housewares, LLC, Los Angeles). Inoculum was homogeneously mixed into both pasteurized and nonpasteurized GC orchard soil at a rate of $0.25 \%$ (wt/wt) along with the carbon amendment. Viability of the inoculum was determined immediately prior to soil infestation by spreading 20,25 , and $30 \mathrm{mg}$ of ground inoculum on onefifth-strength potato dextrose agar amended with ampicillin (Fisher Scientific, Pittsburg) and streptomycin (Sigma-Aldrich, St. Louis) at $100 \mu \mathrm{g} \mathrm{ml}^{-1}$ and kanamycin (Sigma-Aldrich) at $75 \mu \mathrm{g} \mathrm{ml}^{-1}$. CFU of $R$. solani AG-5 were assessed after $48 \mathrm{~h}$ of incubation at room temperature. Relative abundance of the pathogen in soil after ASD treatment was determined by real-time quantitative polymerase chain reaction (qPCR), as described below.

ASD treatment. ASD was conducted essentially as described by Hewavitharana et al. (2014) and utilized a two-way treatment structure in a complete randomized design. The two factors were soil pasteurization status (pasteurized or nonpasteurized) and carbon amendment. In reference to this experiment, pasteurized and nonpasteurized treatment counterparts of the same carbon source and no-treatment control are denoted with $\mathrm{P}$ or NP, respectively, followed by the corresponding soil treatment. For soil pasteurization, moistened soil was placed in a plastic bag and heated overnight in an oven at $85^{\circ} \mathrm{C}$ on two successive days. After pathogen infestation and carbon amendment at rates given above, soils were placed in 1.2-liter plastic pots and all soils were watered to field capacity, with the exception of the ET treatment. For the latter, water volume required to attain field capacity was adjusted to account for the $100 \mathrm{ml}$ of $10 \%$ ET solution added to each pot. All pots were sealed in a double layer of gas-impermeable transparent Saranex bags ( 17.8 by $20.3 \mathrm{~cm}$, Bitran Series "S" bags; Com-Pac International Carbondale, IL). Soils were incubated for 2 weeks in controlled environment chambers using a temperature regime of $24^{\circ} \mathrm{C}$ (day) and $18^{\circ} \mathrm{C}$ (night) with a 12 -h photoperiod and a 
photosynthetically active radiation of $225 \mu \mathrm{mol} \mathrm{s}^{-1} \mathrm{~m}^{-2}$. At completion of the anaerobic phase, pots were removed from the growth chamber, bags were opened, and oxidation reduction potential (ORP) was measured immediately at $5 \mathrm{~cm}$ of soil depth using an ORP meter (Oakton pH 6 meter, Acorn series; Vernon Hills, IL). A soil sample was collected at the $5-\mathrm{cm}$ depth using a sterile cork borer $(2 \mathrm{~cm}$ in diameter) from which $\mathrm{pH}$ was determined and DNA was extracted. Soil $\mathrm{pH}$ was determined in a 1:1 soil-water solution. The initial trial consisted of five replicates and the second trial possessed three replicates per soil treatment. A no-treatment control was conducted under aerobic conditions for this experiment.

Seedling cultivation. Plant bioassays were conducted using 'Gala' apple seedlings. Apple fruit were harvested in September 2008 from an 11-year-old planting of Gala/M26 at the CV orchard and stored in a cold room at 0 to $1^{\circ} \mathrm{C}$. Seed extraction, disinfection, and stratification were conducted as previously described (Hewavitharana et al. 2014). Stratified seed were sown in plastic planting trays filled with pasteurized potting mix (peat moss and perlite; McConkey, Sumner, WA), soil was moistened with tap water, and trays were wrapped in plastic film to retain moisture. Trays were transferred to an incubator and plants were grown under a 12-h photoperiod at a constant $24^{\circ} \mathrm{C}$. The plastic wrap was removed upon seedling contact and plants were watered every other day thereafter. Seedlings were 5 weeks old at the time of use in assays.

Effect of carbon source type on ASD efficacy. The experimental outline of these studies is presented in Figure 1. At completion of the 2-week ASD incubation period, soils were aerated in pots for an additional 2 weeks while maintaining soil moisture by watering $50.0 \mathrm{ml}$ to each pot every other day. In the initial trial, five apple seedlings were transplanted into each pot and grown for 5 weeks in environmental growth chambers under the conditions noted above. In the second trial, for each treatment, soils from three replicate pots were pooled, mixed thoroughly, and then redistributed into 10 individual 164.0-ml tapered tubes (Ray Leach Cone-tainers; Stuewe and Sons Inc., Corvallis, OR), and one apple seedling was transplanted into each tube and grown for 4 weeks using the same conditions as above. Seedlings were watered every other day with $100 \mathrm{ml}$ into pots and $10 \mathrm{ml}$ into tapered tubes in the first and the second trials, respectively. At harvest, plant roots were washed to remove soil particles, and shoot length and seedling weight were measured. A representative sample of 10 root segments $(0.5$ to $1.0 \mathrm{~cm}$ in length) per seedling was plated on water agar (WA) amended with kanamycin $\left(75 \mu \mathrm{g} \mathrm{ml}^{-1}\right)$ in duplicate. Plates were incubated at room temperature and hyphal growth from root segments was observed daily with a compound microscope $(\times 100$; Olympus $\mathrm{BH} 2$ series system) to determine the incidence of $R$. solani AG-5 root infection.

Assessment of GR input level on ASD induced control of R. solani AG-5. Oat grain inoculum of $R$. solani AG-5 was homogeneously mixed into soil at a level of $0.25 \%$ (wt/wt) for $5 \mathrm{GR}$, 10GR, 20GR, no-treatment anaerobic control (ANC), no-treatment aerobic control (AC), and pasteurized control (PC) treatments in the first trial and at $0.5 \%$ (wt/wt) in the second trial for all treatments except PC. For 5GR, 10GR, and 20GR treatments, soils were amended with GR, as noted above. Soils of all treatments except AC were watered to field capacity $(290 \mathrm{ml})$. For the AC treatment, soil was moistened with $100 \mathrm{ml}$ of water and incubated without bagging the pots. Pots were arranged in a complete randomized design inside environmental growth chambers. ASD phase, soil phytochemical measurements, soil inoculum determination, posttreatment aeration, and plant growth in two trials were conducted as mentioned previously in the plant assay for multiple carbon sources. Quantity of $R$. solani AG-5 DNA in soil after ASD treatment was determined in trial 2. The experimental outline of these studies is presented in Figure 2.

Determination of $\boldsymbol{R}$. solani AG-5 inoculum density. Relative persistence of $R$. solani AG-5 inoculum among treatments at completion of the ASD process was assessed by qPCR using DNA extracted from soil. For each replicate pot described above, a 5-g soil sample was obtained and DNA was extracted using the PowerMax soil DNA isolation kit (MO BIO Laboratories Inc., Carlsbad, CA). $R$. solani AG-5 DNA was quantified by qPCR analysis using the primer pair RsAG5F (5'-GAT ATT TGT AGC

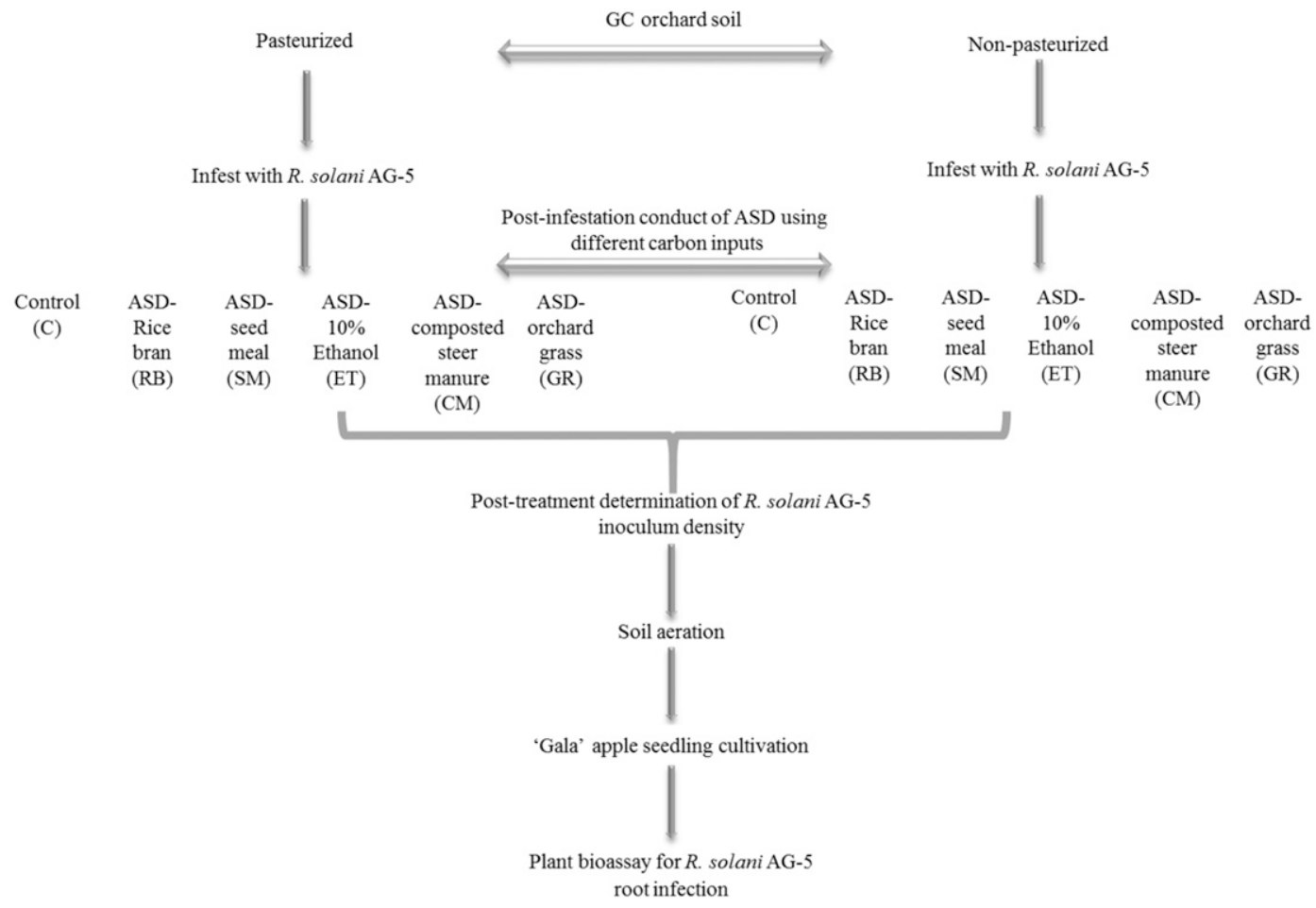

Fig. 1. Experimental protocol utilized to assess the effect of soil pasteurization and carbon input type on the efficacy of anaerobic soil disinfestation (ASD) for the control of Rhizoctonia solani AG-5. Assays were conducted in a commercial (GC) orchard soil located in Washington State using Gala apple seedlings as the susceptible indicator plant. 
TGG CTC ATG-3') and RsAG5R (5'-GCA CCA ATT GTT CTT AAA AAA CAA TC- $3^{\prime}$ ), with the reaction mixture and amplification conditions as previously described (Mazzola and Zhao 2010). A standard curve was prepared from purified DNA of $R$. solani AG-5 isolate 5-104 diluted from DNA at $0.1 \mathrm{ng} \mu \mathrm{l}^{-1}$ to $10 \mathrm{fg}^{\mathrm{N}} \mathrm{l}^{-1}$.

Microbial community analyses. Microbial communities were assessed using terminal restriction fragment length polymorphism (T-RFLP) (fungal communities) and amplicon sequencing (fungal and bacterial communities) of DNA extracted from GC soil immediately after completion of the anaerobic phase of ASD in trial 1. Pasteurized and nonpasteurized GR, CM, and control treatments were selected based on their contrasting disease control efficacy and effect on mean seedling weight. DNA was extracted from 5-g soil samples as described above.

T-RFLP analysis was performed on DNA pooled from the five replicates for each treatment. Fungal DNA was amplified using the fluorescently labeled internal transcribed spacer (ITS) $1 \mathrm{~F}$ (5'-CTT GGT CAT TTA GAG GAA GTA A-3') (Gardes and Bruns 1993) and ITS4 (5'-TCC TCC GCT TAT TGA TAT GC-3') primer pair, and digestion of resulting amplicons, separation of fragments using the CEQ 8000 Genetic Analysis System (Beckman-Coulter, Brea, $\mathrm{CA}$ ), and cluster analysis of resulting T-RFLP profiles was conducted as described by Weerakoon et al. (2012).

Amplicon sequencing was performed for each of the five treatment replicates. The V4 variable region of the bacterial 16S ribosomal RNA gene was amplified using the primer pair $515 f\left(5^{\prime}\right.$-GTG CCA GCM GCC GCG GTA A-3') and 806r (5'-GGA CTA CHV GGG TWT CTA AT- $3^{\prime}$ ) (Caporaso et al. 2011). The fungal ITS region was amplified using the primers ITS1F-Bt1 (5'-TCC GTA GGT GAA CCT GCG G-3') and ITS4Rbt (5'-TCC TCC GCT TAT TGA TAT GC-3') (White et al. 1990). Sample-specific barcodes were added to the forward primer. The PCR conditions were as follows: $94^{\circ} \mathrm{C}$ for $3 \mathrm{~min} ; 28$ cycles of $94^{\circ} \mathrm{C}$ for $30 \mathrm{~s}, 53^{\circ} \mathrm{C}$ for $40 \mathrm{~s}$, and $72^{\circ} \mathrm{C}$ for $1 \mathrm{~min}$; with a final elongation step at $72^{\circ} \mathrm{C}$ for $5 \mathrm{~min}$. PCR products were visualized on a $2 \%$ agarose gel to verify the amplicon size. Multiple samples were pooled together in equal proportion based on molecular weight and DNA concentration and purified using Ampure XP beads (Agencourt Bioscience Corporation, Beverly, MA). Pooled and purified PCR products (10 ng from each sample) were then used to prepare a DNA library following the Illumina TruSeq DNA library preparation protocol (Illumina, San Diego, CA). All sequencing was performed by Molecular Research LP (Shallowater, TX) using the Illumina MiSeq platform and sequencing data were processed as previously described (Mazzola et al. 2015). Sequence data were refined by removing Archaea, chloroplast, mitochondrial sequences, singletons, and doubletons. Explicet software (Robertson et al. 2013) was used to conduct statistical analysis and visualization of microbiome data. The $\alpha$ diversity was determined using minimum library size as the cut off size with 1,000-bootstrap resampling. A two-part test (Wagner et al. 2011) was conducted after making filters for each bacterial and fungal library of nonpasteurized control (NPC), PC, GR nonpasteurized (GRNP), GR pasteurized (GRP), CM nonpasteurized (CMNP), and $\mathrm{CM}$ pasteurized (CMP) treatments and comparing them with each other, with a $P$ value threshold of 0.05 .

Determination of $P$. penetrans suppression by ASD. Populations of $P$. penetrans were amplified in SR orchard soil prior to application of ASD using the following protocol. Subsamples $(900 \mathrm{~g})$ of SR orchard soil were filled into 30 pots, and five Gala apple seedlings of 5 and 13 weeks in age were randomly planted into each pot. Seedlings were grown for 5 weeks using the conditions noted above. All seedlings were removed after the nematode amplification

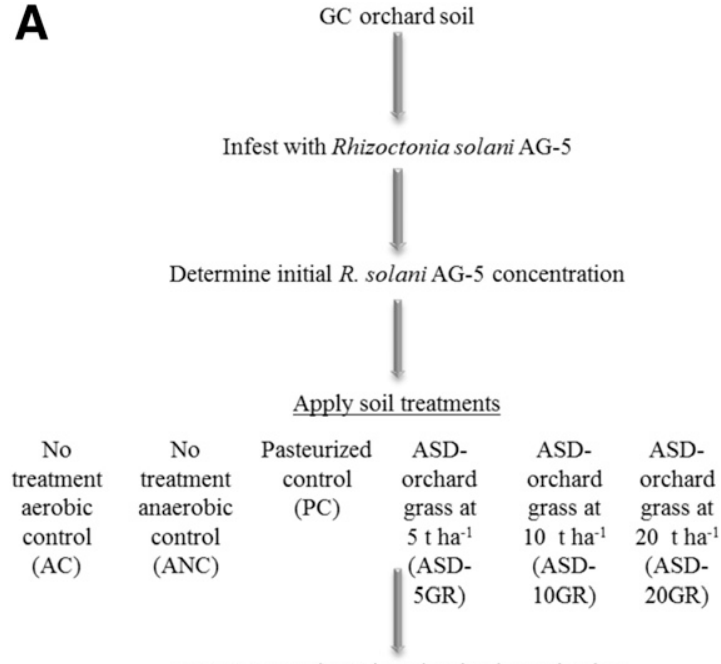

Post-treatment inoculum density determination

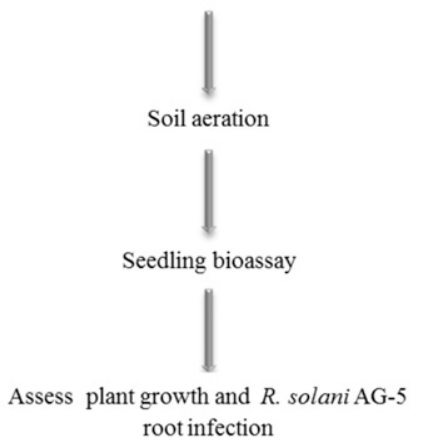

B

Sunrise orchard soil

Cultivate soil with 'Gala' seedlings to increase natural inoculum of Pratylenchus. penetrans

Determination of pre-treatment $P$. penetrans soil density

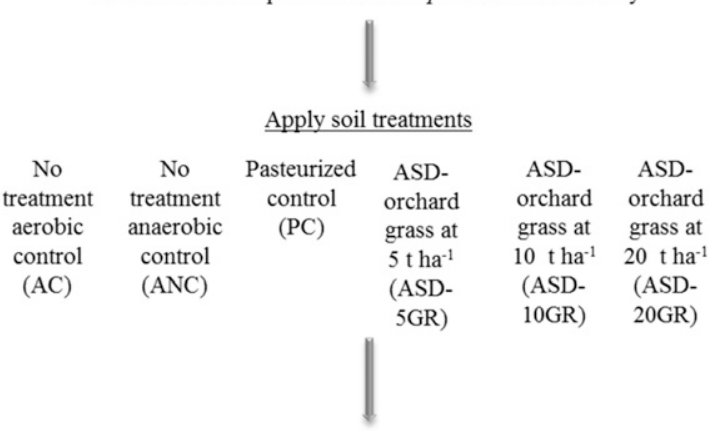

Soil aeration

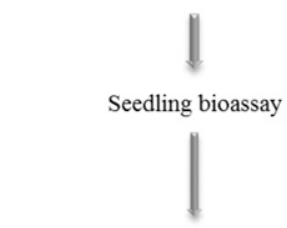

Assess plant growth and $P$. penetrans root density

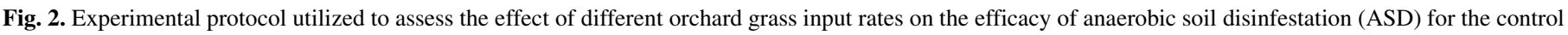

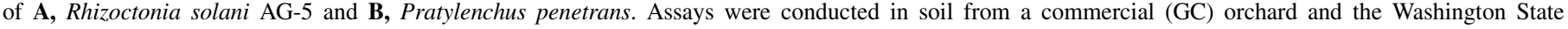
University Sunrise Orchard, respectively, located in Washington State using Gala apple seedlings as the susceptible indicator plant. 
treatment and five pots were randomly assigned to each treatment. For the PC treatment, pooled, moistened soil from five pots was pasteurized as described above. After amending the soil with different levels of GR (i.e., 5GR, 10GR, and 20GR) as noted previously, soils were watered to field capacity $(200 \mathrm{ml})$ for all treatments, including the ANC, AC and PC soils were moistened with $100 \mathrm{ml}$ of water and incubated without bagging. Other treatments were applied as described above.

At completion of the ASD process, soil aeration, moisture maintenance before seedling transplantation, seedling transplantation, plant growth conditions, and irrigation were conducted as above. Seedlings were grown for a period of 6 weeks. At harvest, plant roots were washed to remove soil particles and shoot length and seedling weights were measured. $P$. penetrans nematodes were extracted and counted from pooled $0.5 \mathrm{~g}$ of root samples in duplicate for each of five replicates per treatment (Mazzola 1998). A 100-g soil sample was collected from each of the five replicate pots for each treatment. Nematodes were extracted from soil using the modified pie-pan method, a modification of the Baermann funnel technique (Mazzola 1998). Nematodes were collected by filtering the soil extract twice through a 500-mesh sieve and backwashing into a counting dish. The number of $P$. penetrans nematodes was determined by counting under a microscope (Olympus BH2) at $\times 40$.

Data analysis. The studies were conducted and analyzed as two independent trials. Data were analyzed using the SAS (SAS Institute Inc., Cary, NC) statistical package and employed analysis of variance (ANOVA) with ordinary least squares method or maximum-likelihood estimates for ordinal data. When data were not normal or variances were not homogeneous, data transformation, Friedman's test to conduct ANOVA using ranked responses, or the Proc mixed method were used accordingly. Mean separation was based on the Fisher's least significant difference method. PAST software package, version 2.14 (Hammer et al. 2001), was used to conduct nonmetric multidimensional scaling analysis of bacterial and fungal operational taxonomic unit (OTU) data and to determine measures of fungal and bacterial community diversity. The $\beta$ diversity index ThetaYC (Yue and Clayton 2005) was used to assess similarity of bacterial and fungal OTU libraries among soil treatments. Heat maps of relative dissimilarity among libraries were generated using Explicet visualization software (Robertson et al. 2013), with ThetaYC having a scale ranging from 0 (identical overlap) to 1 (no shared OTU) between two libraries.

\section{RESULTS}

Effect of ASD carbon source on disease control. At completion of the anaerobic phase, soil $\mathrm{pH}$ was relatively low in all ASD treatments compared with the no-amendment control, with the exception of CM treatment, regardless of soil pasteurization (Table 1). Nonpasteurized ASD-treated soil possessed a lower $\mathrm{pH}$ relative to its pasteurized counterpart for all carbon amendments. Measured ORP values for all the carbon-amended treatments were lower than the calculated ORP values based on corresponding $\mathrm{pH}$ values (Table 1), indicating the reductive nature in treated soil (Butler et al. 2012b).

No significant interaction between soil pasteurization status and ASD carbon input was observed relative to the quantity of $R$. solani AG-5 DNA detected in soil posttreatment. All ASD treatments that included a carbon source input significantly reduced the quantity of $R$. solani AG-5 DNA detected relative to the no-amendment control (Fig. 3A). The quantity of $R$. solani AG-5 DNA detected in GR-and ET-treated soil was similar but significantly lower than in the RB, SM, and CM treatments. The mean quantity of pathogen DNA detected in soil varied over 1,000-fold between effective pathogen suppressive treatments (ET, GR, SM, and RB) and the no-treatment control and CM treatment. ASD carbon source input had a significant effect on level of seedling root infection detected in soil artificially infested with $R$. solani AG-5. With the exception of $\mathrm{CM}$, all ASD treatments significantly reduced root infection relative to the no-treatment control (Fig. 3B). Resulting seedling biomass was significantly affected by ASD treatment in a carbonsource-dependent manner, with the GR and SM treatments significantly enhancing plant biomass relative to the no-treatment control (Fig. 3C). In contrast, the CM, ET, and RB ASD treatments did not substantially improve plant growth. The effect of soil pasteurization on disease development was variable, with a significantly higher incidence of disease in pasteurized soil observed in one of the two trials. In the second trial, the percent $R$. solani AG-5 root infection in pasteurized GC soil was $8.1 \%$, compared with $0.0 \%$ in the nonpasteurized soil. Soil pasteurization status had no significant effect on apple seedling biomass (data not shown).

Because the ASD-GR treatment provided superior control of $R$. solani AG-5 relative to other ASD treatments, it was selected for use in studies to address the effect of input rate on disease control efficacy. $R$. solani AG-5 inoculum density established in GC orchard soil was 0.6 and $2.8 \mathrm{CFU} \mathrm{g} \mathrm{g}^{-1}$ of soil for trial 1 and trial 2, respectively. The higher density was intentionally established in trial 2 due to the absence of significant root infection detected in the initial experiment. At completion of the ASD process in trial 2, there were significant $(P<0.0001)$ differences among treatments in quantity of $R$. solani AG-5 detected in soil (Table 2). The AC treatment contained significantly higher amounts of pathogen DNA than all other treatments. Quantity of pathogen DNA in ASDtreated soils at different rates of GR application was biologically comparable with that obtained in response to soil pasteurization. Seedling root infection by $R$. solani AG-5 occurred at very low levels in the first trial and did not differ significantly among treatments (Table 2). In the second trial, all soil treatments significantly $(P<0.0001)$ reduced $R$. solani AG-5 seedling root infection relative to the AC treatment but there were no differences among ASD-GR input levels (Table 2).

Significant differences in growth of seedlings planted in soil artificially infested with $R$. solani AG-5 were observed among soil treatments, including seedling weight and shoot length (Table 2) in both trials. In the first trial, ASD enhanced seedling biomass regardless of GR input rate in a manner similar to the PC treatment but only 20GR resulted in seedling biomass that was significantly greater than the AC treatment (Table 2). In trial 2, all ASD treatments improved seedling biomass relative to AC, and seedling weight and shoot length for the ASD-20R treatment were superior to all other treatments.

In ASD-GR input rate trials, initial $P$. penetrans densities averaged $2 \mathrm{~g}^{-1}$ of soil and did not change over the 5-week apple seedling growth period. In contrast, $P$. penetrans nematodes were

TABLE 1. Soil $\mathrm{pH}$, average oxidation reduction potential (ORP), and corresponding critical redox potential (CEh) values as determined at completion of a 2-week anaerobic soil disinfestation period in GC orchard soil ${ }^{\mathrm{x}}$

\begin{tabular}{lcccc}
\hline $\begin{array}{l}\text { Carbon } \\
\text { amendment }^{\mathrm{y}}\end{array}$ & $\begin{array}{c}\text { Soil } \\
\text { status }^{\mathrm{z}}\end{array}$ & $\mathrm{pH}$ & $\begin{array}{c}\text { Measured ORP } \\
\text { value/mV }\end{array}$ & $\mathrm{CEh} / \mathrm{mV}$ \\
\hline $\mathrm{C}$ & $\mathrm{P}$ & $5.96 \pm 0.00 \mathrm{~b}$ & $-31.0 \pm 36.77 \mathrm{~d}$ & $237.40 \mathrm{~d}$ \\
RB & $\mathrm{P}$ & $5.29 \pm 0.04 \mathrm{~cd}$ & $-14.0 \pm 55.15 \mathrm{~cd}$ & $277.90 \mathrm{bc}$ \\
SM & $\mathrm{P}$ & $5.45 \pm 0.11 \mathrm{c}$ & $-8.0 \pm 15.56 \mathrm{bcd}$ & $268.30 \mathrm{c}$ \\
ET & $\mathrm{P}$ & $5.25 \pm 0.15 \mathrm{~d}$ & $54.0 \pm 1.41 \mathrm{ab}$ & $280.30 \mathrm{~b}$ \\
GR & $\mathrm{P}$ & $5.32 \pm 0.06 \mathrm{~cd}$ & $-32.5 \pm 10.61 \mathrm{~d}$ & $275.80 \mathrm{bc}$ \\
CM & $\mathrm{P}$ & $6.51 \pm 0.04 \mathrm{a}$ & $-46.0 \pm 46.67 \mathrm{~d}$ & $204.70 \mathrm{e}$ \\
C & NP & $6.07 \pm 0.10 \mathrm{~b}$ & $38.0 \pm 1.41 \mathrm{abc}$ & $231.10 \mathrm{~d}$ \\
RB & NP & $4.97 \pm 0.01 \mathrm{e}$ & $59.0 \pm 15.56 \mathrm{a}$ & $297.10 \mathrm{a}$ \\
SM & NP & $5.27 \pm 0.01 \mathrm{~d}$ & $-120.0 \pm 0.00 \mathrm{e}$ & $279.10 \mathrm{~b}$ \\
ET & NP & $4.89 \pm 0.10 \mathrm{e}$ & $9.0 \pm 18.38 \mathrm{abcd}$ & $301.90 \mathrm{a}$ \\
GR & NP & $5.27 \pm 0.01 \mathrm{~cd}$ & $12.0 \pm 1.41 \mathrm{abcd}$ & $278.80 \mathrm{bc}$ \\
CM & NP & $6.43 \pm 0.16 \mathrm{a}$ & $-14.0 \pm 57.98 \mathrm{~cd}$ & $209.20 \mathrm{e}$ \\
\hline
\end{tabular}

$\mathrm{x}$ All data represent results from trial $1(n=5)$. Means in a column followed by the same letter are not significantly $(P>0.05)$ different.

y $\mathrm{C}=$ no-amendment control, $\mathrm{CM}=$ composted steer manure, $\mathrm{ET}=10 \%$ ethanol, GR = orchard grass, $\mathrm{RB}=$ rice bran, and $\mathrm{SM}=$ Brassica juncea seed meal.

z $\mathrm{P}$ and NP indicate the soil status as pasteurized and nonpasteurized, respectively. 
recovered from apple seedling roots at a density of $1,493 \mathrm{~g}^{-1}$ of root at the end of the amplification treatment prior to conducting ASD. At harvest of apple seedlings planted in ASD-treated soils, rootlesion nematode soil densities for the ASD-5GR treatment were comparable with the controls and significantly higher than the ASD-10GR or ASD-20GR treatments in trial 1 (Table 3). The ASD10GR and ASD-20GR treatments possessed $P$. penetrans root densities that were comparable with the PC treatment in trial 1. At
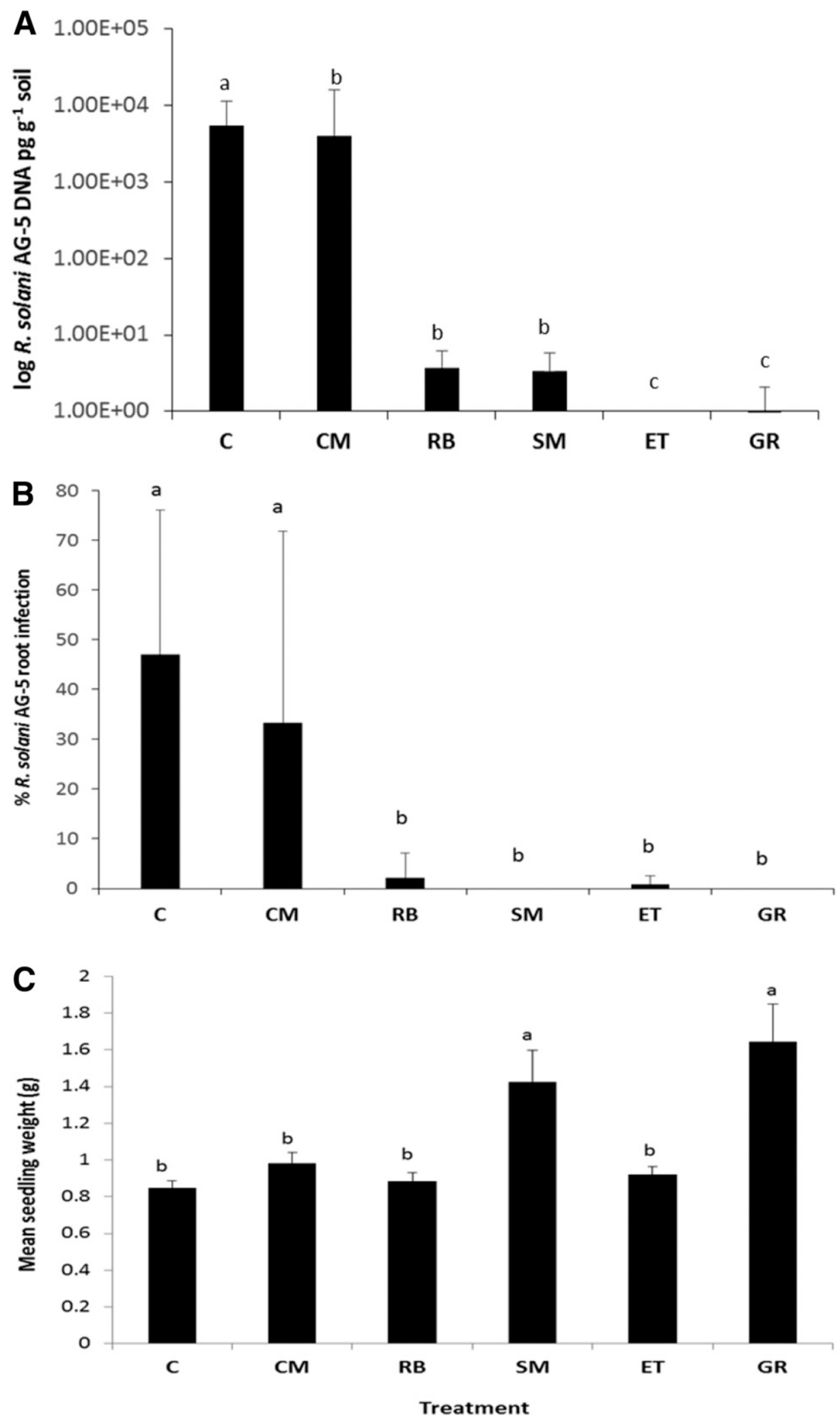

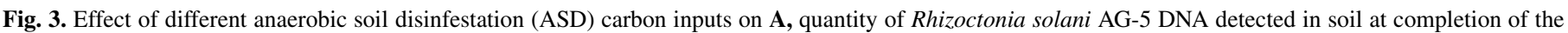
anaerobic phase; B, percent Gala apple seedling root infection by $R$. solani AG-5; and $\mathbf{C}$, biomass of Gala apple seedlings grown in GC orchard replant soil. Soil was artificially infested with $R$. solani AG-5 prior to application of ASD treatments. Soil treatments included a no-treatment control (C) and ASD conducted using the following inputs; $\mathrm{CM}=$ composted steer manure, $10.08 \mathrm{t} \mathrm{ha}^{-1} ; \mathrm{RB}=$ rice bran, $4.4 \mathrm{t} \mathrm{ha}^{-1} ; \mathrm{SM}=$ Brassica juncea seed meal, $4.4 \mathrm{t} \mathrm{ha}{ }^{-1} ; \mathrm{ET}=10 \%$ ethanol; and $\mathrm{GR}=$ orchard grass, $20 \mathrm{t} \mathrm{ha}^{-1}$. Means designated with the same letter are not significantly $(P>0.05)$ different. 
harvest, there was a significant $(P<0.0001)$ difference between $P$. penetrans root densities among treatments in both trials, and densities were significantly higher in ASD-5GR and AC treatments than all other treatments in trial 2 (Table 4). Root densities of P. penetrans for the ASD-10GR and ANC treatments were statistically comparable with each other but lower than that of the ASD-5GR treatment for the first trial. The 20GR treatment provided a level of lesion nematode control that was statistically comparable with PC treatment. Nevertheless, all three amendment levels of GR yielded a level of $P$. penetrans suppression that was comparable with the PC treatment and superior to $\mathrm{AC}$ and ANC treatments in trial 2 (Table 4). Different GR input rates did not significantly affect efficacy of ASD in reducing $P$. penetrans root densities in trial 2.

In response to suppression of $P$. penetrans, significant differences in plant growth were observed among soil treatments, including seedling weight and shoot length (Table 4). Increased rate of ASDGR input did not significantly affect seedling weight (Table 4). Soil pasteurization resulted in the highest seedling weight but at least one ASD-GR treatment provided a seedling weight or shoot length growth response that was significantly greater than AC. (Table 4). The ASD-5GR treatment did not significantly improve seedling weight relative to $\mathrm{AC}$ in either trial.

Effect of carbon source and soil pasteurization on soil microbial communities following ASD. T-RFLP profiles of the fungal soil communities from composited treatment replicates are shown in Figure 4. Fungal communities from the PC and CMP treatments were more similar to each other than their nonpasteurized counterparts, yet all $\mathrm{AC}$ and $\mathrm{CM}$ treatments grouped regardless of pasteurization. The communities from GR-input soils were distinct from the other treatments regardless of pasteurization status. Similar groupings of the composited samples were observed by analysis of the individual replicates.

Amplicon sequencing of the individual treatment replicates for the fungal communities confirmed the clustering patterns observed by T-RFLP. Fungal communities in GR-treated soils were distinct from those of control and CM-treated soils (Fig. 5), both of which were overlapping. These distinctions were observed regardless of soil pasteurization status, with the GR treatment forming a distinct cluster in both soil systems. Fungal communities in GR-treated soil samples, with the exception of sample GRP4, were highly similar, regardless of soil pasteurization conducted prior to application of ASD, and were dissimilar to the communities detected in the control or CM-treated soils (Fig. 6). ASD treatments induced responses to bacterial community structure similar to those observed for fungal communities (Fig. 7). In a given soil, GR samples formed a unique cluster regardless of soil pasteurization conducted prior to application of ASD. Bacterial communities from the no-treatment control and CM treatment were more similar to each other than the GR treatment. There was a greater degree of similarity between control and CM bacterial communities in nonpasteurized soil than that detected for the corresponding treatments in pasteurized soils (Fig. 6). The bacterial community from the pasteurized soil control treatment was more similar to that of the GR treatment than either the nonpasteurized control or either CM treatment.

Sequence data sets of the fungal communities exhibited significant diversity among treatments in terms of OTU content, species diversity, and species richness. Pasteurization prior to ASD treatment significantly reduced the number of fungal OTU in the control and CM treatments but had no effect in GR (Table 5). Comparatively, pasteurization resulted in a significant decrease in bacterial OTU only in the control. Examination of the nonpasteurized soils indicated that GR input resulted in fungal (Table 5) and bacterial (Table 6) communities that were less diverse and possessed lower richness than the control or CM soils. The nonpasteurized control and $\mathrm{CM}$ treatments possessed similar qualities in terms of fungal and bacterial community richness and diversity, both of which were significantly greater than the GR treatment. Pasteurization of soil prior to ASD application had limited to no effect on resulting bacterial and fungal community measures for soils that received the GR treatment. Pasteurization reduced the richness and diversity of the fungal community detected in both the control and CM-treated soils as well as the bacterial community in the control soil. However, ASD conducted with CM in pasteurized or nonpasteurized soils resulted in similar number of bacterial OTU and Chao 1 index value (Chao 1984).

The Ascomycota phylum represented the most abundant fungal group detected in GR-treated soil, encompassing $>97 \%$ of sequences detected regardless of pasteurization prior to application of ASD. In GRNP and GRP soils, members of the class Sordariomycetes represented 65 to $95 \%$ of the fungal sequences detected among the total. The primary differences between pasteurized and nonpasteurized GR soil samples were the detection of members of Saccharomycetes in the pasteurized GR treatment and a greater abundance of members of Dothideomycetes in the nonpasteurized GR treatment. Pezizomycete sequences represented less than $0.1 \%$ of sequences from all nonpasteurized GR soil samples but accounted for 1 to $20 \%$ of sequences from the nonpasteurized CM and control soil samples. Similarly, members of Orbiliomycetes

TABLE 3. Pratylenchus penetrans soil density at completion of a 5-week apple seedling growth period in Sunrise Orchard soil

\begin{tabular}{lc}
\hline Treatment & \\
\hline PC & Number of nematodes ${ }^{\mathrm{z}}$ \\
AC & $0.0 \mathrm{~b}$ \\
ANC & $52.7 \mathrm{a}$ \\
ASD-5GR & $51.6 \mathrm{a}$ \\
ASD-10GR & $47.4 \mathrm{a}$ \\
ASD-20GR & $0.0 \mathrm{~b}$ \\
\hline
\end{tabular}

y Treatments: $\mathrm{PC}=$ pasteurized control; $\mathrm{AC}=$ aerobic control; $\mathrm{ANC}=$ anaerobic control; ASD = anaerobic soil disinfestation; and 5GR, 10GR, and $20 \mathrm{GR}=$ orchard grass application at 5,10 , and $20 \mathrm{t} \mathrm{ha}^{-1}$.

${ }^{\mathrm{z}}$ P. penetrans nematodes were recovered from apple root zone orchard soil and recorded as number per $100 \mathrm{~g}$ of soil. Values are means of five replicates, and means followed by the same letter are not significantly $(P>$ $0.05)$ different.

TABLE 2. Effect of different orchard grass input levels used in anaerobic soil disinfestation (ASD) on quantity of Rhizoctonia solani AG-5 DNA detected in artificially infested GC orchard soil, Gala apple seedling root infection by the introduced pathogen (Infection), seedling weight (Weight), and seedling shoot length (Length) ${ }^{\mathrm{y}}$

\begin{tabular}{|c|c|c|c|c|c|c|c|}
\hline \multirow[b]{2}{*}{ Treatment $^{\mathrm{z}}$} & \multicolumn{3}{|c|}{ Trial 1} & \multicolumn{4}{|c|}{ Trial 2} \\
\hline & Infection $(\%)$ & Weight (g) & Length $(\mathrm{cm})$ & DNA (pg g ${ }^{-1}$ soil) & Infection $(\%)$ & Weight (g) & Length $(\mathrm{cm})$ \\
\hline $\mathrm{PC}$ & $17.6 \mathrm{a}$ & $0.78 \mathrm{a}$ & $10.11 \mathrm{a}$ & $0.0000 \mathrm{c}$ & $0.0 \mathrm{~b}$ & $1.13 \mathrm{~cd}$ & $8.89 \mathrm{~b}$ \\
\hline $\mathrm{AC}$ & $4.4 \mathrm{a}$ & $0.66 \mathrm{~b}$ & $8.94 \mathrm{bc}$ & $0.1351 \mathrm{a}$ & $62.0 \mathrm{a}$ & $1.10 \mathrm{~d}$ & $7.87 \mathrm{~b}$ \\
\hline ANC & $2.8 \mathrm{a}$ & $0.55 \mathrm{c}$ & $8.25 \mathrm{c}$ & $0.0070 \mathrm{~b}$ & $0.0 \mathrm{~b}$ & $1.56 \mathrm{~b}$ & $8.63 \mathrm{~b}$ \\
\hline ASD-5GR & $0.4 \mathrm{a}$ & $0.71 \mathrm{ab}$ & $9.79 \mathrm{a}$ & $0.0018 \mathrm{c}$ & $0.0 \mathrm{~b}$ & $1.45 \mathrm{bc}$ & $8.48 \mathrm{~b}$ \\
\hline ASD-10GR & $0.0 \mathrm{a}$ & $0.74 \mathrm{ab}$ & $9.68 \mathrm{ab}$ & $0.0115 \mathrm{~b}$ & $0.0 \mathrm{~b}$ & $1.54 \mathrm{~b}$ & $8.83 \mathrm{~b}$ \\
\hline ASD-20GR & $0.0 \mathrm{a}$ & $0.80 \mathrm{a}$ & $9.80 \mathrm{a}$ & $0.0129 \mathrm{~b}$ & $0.0 \mathrm{~b}$ & $1.91 \mathrm{a}$ & $10.37 \mathrm{a}$ \\
\hline
\end{tabular}

y Means in a column followed by the same letter are not significantly $(P>0.05)$ different.

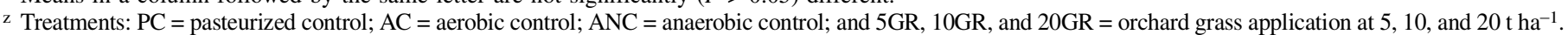


were abundant in the $\mathrm{CM}$ and control nonpasteurized soils but were not detected in the GR soil samples. In nonpasteurized soil, the Basidiomycota phylum represented 1 to $4 \%$ of fungal sequences from the CM treatment and 4 to $20 \%$ of sequences from the control treatment. Sequences representing this phylum were nearly absent in soils that received the GR treatment, comprising less than $1 \%$ of sequences detected in all samples. An increased abundance of Basidiomycota fungi in pasteurized soils was directly related to elevated detection of sequences corresponding to the introduced pathogen $R$. solani AG-5. Basidiomycota fungi represented $77 \%$ of sequences detected in one pasteurized $\mathrm{CM}$ treatment sample.

Soil treatments differed significantly $(P<0.05)$ in the abundance of sequences representing notable potentially plant-pathogenic fungi. Among the total 2.82 million fungal sequences, $6.77 \%$ were identified as Fusarium oxysporum, and this species accounted for $15.58,13.46$, and $0.23 \%$ of the sequences from the CM, control, and GR treatments, respectively. $R$. solani accounted for 3.12, 9.55, and $0.03 \%$ of sequences from the CM, control, and GR treatments. Abundance of Ilyonectria robusta or Cylindrocarpon spp. sequences was greatest in CM-treated (1.64\%) and control (0.67\%) soil, and were virtually undetected from GR $(0.003 \%)$ soil.

Among the fungal OTU detected in this study, there were 57 and 49 OTU that differed significantly $(P<0.05)$ in abundance between the CMNP and GRNP, and NPC and GRNP treatments, respectively. Notably, Coprinellus curtus, a basidiomycete shown to have activity against $R$. solani and Fusarium sp. (Nakasaki et al. 2007),

TABLE 4. Effect of different grass input levels used in anaerobic soil disinfestation (ASD) on densities of Pratylenchus penetrans detected in Gala apple seedling roots (Nematodes), seedling weight (Weight), and seedling shoot length (Length) in assays conducted in naturally infested Sunrise orchard soil ${ }^{\mathrm{y}}$

\begin{tabular}{|c|c|c|c|c|c|c|}
\hline \multirow[b]{2}{*}{ Treatment $^{\mathrm{z}}$} & \multicolumn{3}{|c|}{ Trial 1} & \multicolumn{3}{|c|}{ Trial 2} \\
\hline & Nematodes $\mathrm{g}^{-1}$ of root & Weight $(\mathrm{g})$ & Length $(\mathrm{cm})$ & Nematodes $\mathrm{g}^{-1}$ of root & Weight (g) & Length $(\mathrm{cm})$ \\
\hline PC & $0.4 \mathrm{c}$ & $1.06 \mathrm{a}$ & $10.34 \mathrm{a}$ & $0.0 \mathrm{~b}$ & $1.37 \mathrm{a}$ & $8.93 \mathrm{~b}$ \\
\hline $\mathrm{AC}$ & $154.6 \mathrm{ab}$ & $0.67 \mathrm{~d}$ & $7.28 \mathrm{c}$ & $259.6 \mathrm{a}$ & $1.01 \mathrm{~b}$ & $8.78 \mathrm{~b}$ \\
\hline ASD-5GR & $324.4 \mathrm{a}$ & $0.81 \mathrm{bcd}$ & $7.59 \mathrm{c}$ & $2.4 \mathrm{~b}$ & $0.83 \mathrm{c}$ & $9.09 \mathrm{~b}$ \\
\hline ASD-10GR & $50.6 \mathrm{bc}$ & $0.90 \mathrm{ab}$ & $7.64 \mathrm{c}$ & $0.0 \mathrm{~b}$ & $1.05 \mathrm{bc}$ & $9.20 \mathrm{~b}$ \\
\hline ASD-20GR & $1.2 \mathrm{c}$ & $0.85 \mathrm{bc}$ & $8.98 \mathrm{~b}$ & $0.0 \mathrm{~b}$ & $0.95 \mathrm{bc}$ & $10.22 \mathrm{a}$ \\
\hline
\end{tabular}

y Means in a column followed by the same letter are not significantly $(P>0.05)$ different.

$\mathrm{z}$ Treatments: $\mathrm{PC}=$ pasteurized control; $\mathrm{AC}=$ aerobic control; $\mathrm{ANC}=$ anaerobic control; $\mathrm{ASD}=$ anaerobic soil disinfestation; and 5GR, 10GR, and 20GR $=$ orchard grass application at 5,10 , and $20 \mathrm{t} \mathrm{ha}^{-1}$.

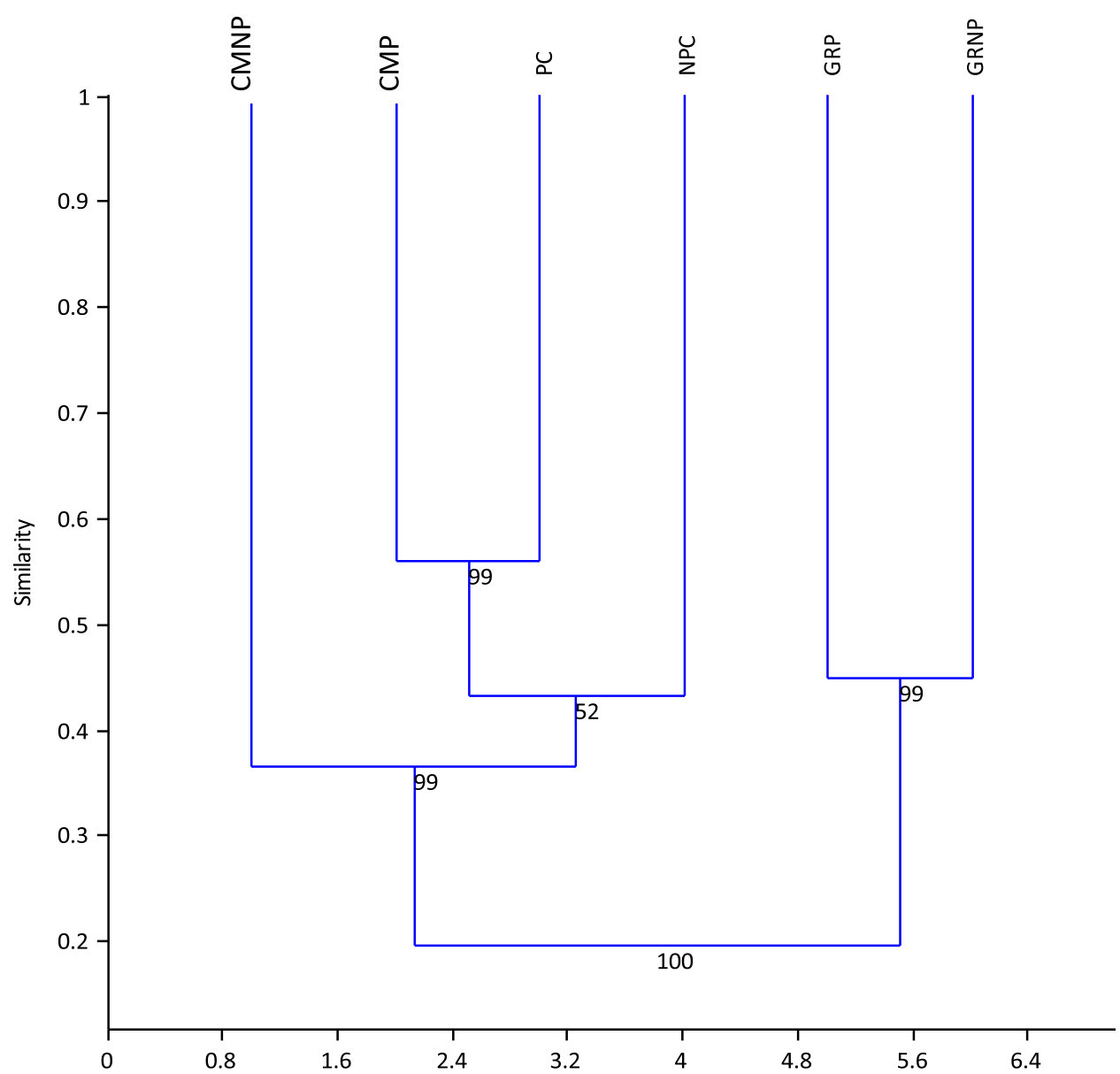

Fig. 4. Effect of pasteurization and different carbon amendments on fungal community similarity in GC orchard soil at completion of a 2-week anaerobic incubation period as characterized by cluster analysis of terminal restriction fragment length polymorphism-derived data. Soils were pasteurized (P) or nonpasteurized (NP) and amended with composted steer manure (CM), orchard grass (GR), or not amended (C) and inundated to field capacity, bagged, and incubated for 2 weeks. The tree was constructed from the Jacquard similarity coefficient of composite profiles from duplicate digestions of a pooled $(n=5)$ DNA sample for each treatment. Bootstrap values are indicated at the tree nodes (based on 10,000 bootstrap replicates). 
was present only in GRNP. Cercophora areolata (Whyte et al. 1996), which produces fungitoxic and cytotoxic metabolites, and Gelasinospora brevispora, which demonstrated antifungal activity toward numerous fungi (Boonsang et al. 2014), were significantly more abundant in the GRNP than CMNP treatment. OTU representing the grass endophyte Preussia spp. (Mapperson et al. 2014; Supaphon et al. 2013) were almost exclusively recovered from the GRP and GRNP treatments. Various species of Penicillium were significantly more abundant in the control and CMNP treatment than the GRNP treatment. Sequences representing the orders Venturiales and Helotiales were detected in CMNP and NPC but not GRNP soil samples. Only eight OTU differed significantly in abundance between the NPC and CMNP treatments. Among those, Pseudallescheria fimeti, which has previously been found in vermicompost (Grantina-Ievina et al. 2013), was more abundant in CMNP compared with NPC. Only two OTU differed significantly in abundance between GRNP and GRP treatments and the CMNP and CMP treatments.

For the bacterial communities, relative frequencies of bacterial divisions and phyla differed among the soil treatments. The NPC and CMNP communities had higher proportions of Acidobacteria, Firmicutes, Verrucomicrobia, Planktomycetes, $\delta$-Proteobacteria, Nitrospirae and SPAM (candidate division) relative to that detected in the GRNP soil. Regardless of prior pasteurization, $\gamma$-Proteobacteria were more abundant in the GR treatments than the other treatments. Soil pasteurization demonstrably reduced the abundance of Acidobacteria, Actinobactera, and SPAM, and generally increased the proportion of Bacteroidetes in the bacterial community across ASD treatments. The candidate division Ws 3 was only apparent in NPC treatment soil. Further differentiation of this group demonstrated that the members of Pseudomonadales were a dominant component of the GRNP bacterial community, accounting for 35 to $60 \%$ of OTU but only 1.5 to $5.5 \%$ of OTU from the CMNP and NPC soil samples, with one exception. Members of Actinomycetales represented 1.5 to $7.1 \%$ of bacterial OTU from the GRNP treatment but only 0.5 to $1.5 \%$ of OTU from the CMNP or NPC treatments.

Among bacterial communities, there were 169 OTU that differed significantly in abundance between the GRNP and NPC treatments, with approximately half being relegated to a specific treatment. Streptosporangium vulgare, which was abundant in GRNP treatment, is a rare actinomycete that has been reported to produce Streptosporangiomycin complex (Coronelli et al. 1975) and Sporacuracin A and B (Atsushi et al. 1975). The dimethyl-sulfide-degrading bacterium Hyphomicrobium facile (Chung et al. 2010) was more abundant in the GRNP soil. Various sulfur-containing compounds, including dimethyl disulfide and dimethyl trisulfide, are generated during the ASD process when GR is used as the carbon input (Hewavitharana et al. 2014). Interestingly, all OTU representing the genus Clostridium were of greater abundance in the NPC than GRNP treatment. The $\mathrm{N}$-fixing and phytohormone-producing bacterium Azotobacter chroococcum was highly abundant in GRNP and has been used as a microbial inoculant, with the goal of enhancing crop production (Wani et al. 2013). Similarly, A. chroococcum was included among the 110 OTU that differed between the GRNP and CMNP treatments, being more abundant in the GRNP treatment. In addition, the tunicamycinproducing actinomycete Streptomyces torulosus was only present in GRNP-treated soil and is known to be active against various plantpathogenic fungi, including $F$. oxysporum and $R$. solani (Atta 2015).

Differences between NPC and CMNP bacterial libraries were confined to OTU that primarily represent generalists. Sequences representing a number of bacteria involved in $\mathrm{N}$ fixation, including Frankia spp., Mesorhizobium loti, and Azospirillum doebereinerae, were more abundant in the CMNP than NPC soil. Luteimonas spp., which reduce nitrite to nitrous oxide (Finkmann et al. 2000), were more abundant in CMNP soil. The sulfide-oxidizing bacterium Thiobacillus sp. was also more abundant in the CMNP-treated soil.

\section{DISCUSSION}

Despite many examples of effective control of soilborne pathogens in response to application of organic amendments (Lazarovits 2001), such disease control has also been reported to be inconsistent (Mazzola and Manici 2012; Tilston et al. 2002), with many studies reporting increased disease incidence (Bonanomi et al. 2007). Similarly, ASD has generated control of certain soilborne pathogens under field conditions but, in other instances in the same cropping system, has failed to yield effective disease control. For instance, although ASD conducted using rice bran as the carbon input has provided effective control of Verticillium dahliae in strawberry (Shennan et al. 2014), the same system has demonstrated significant variability in control of Fusarium wilt of strawberry
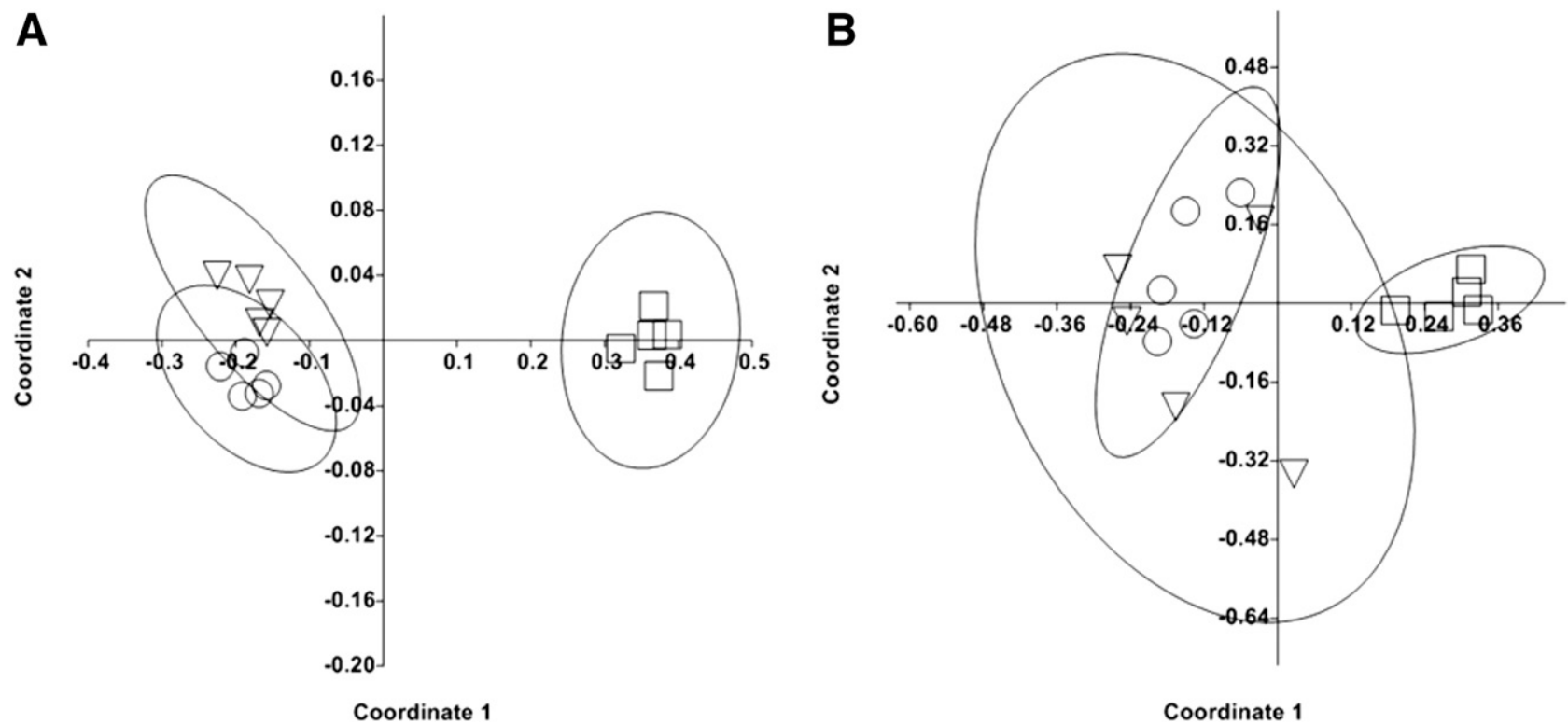

Fig. 5. Effect of anaerobic soil disinfestation on fungal population in A, nonpasteurized and $\mathbf{B}$, pasteurized soil at the completion of the anaerobic phase of incubation as assessed by nonmetric multidimensional scaling of operational taxonomic unit (OTU) data using Bray-Curtis distance metric. OTU were defined as sequences sharing $>97 \%$ similarity with each other. Symbols signify the following treatments: $\bigcirc=$ control, $\nabla=$ composted steer manure, and $\square=$ orchard grass. 
caused by $F$. oxysporum f. sp. fragariae under coastal California climatic conditions (Muramoto et al. 2015). These differential outcomes are likely to result from multiple variables of the system, including modes of action and sensitivity to chemistries produced during the ASD process that may differ in a carbon-input-dependent manner (Hewavitharana et al. 2014).

Under anaerobic conditions, significant suppression of pathogen population density has been observed in response to organic inputs independent of the substrate utilized (Bonanomi et al. 2007). The suppressive effect of organic matter amendments on pathogens under anaerobic conditions was related to production of fungitoxic compounds such as methane, short-chain organic acids, aldehydes, alcohols, and sulfur which are typical products of anaerobic organic matter decomposition (Ponnamperuma 1972). Due to the observation of this fungitoxic compound generation in relation to a wide array of plant materials, it was suggested that microbial anaerobic decomposition results in nonspecific rather than plant-specific fungitoxic compounds (Bonanomi et al. 2007). In contrast, our previous study demonstrated that carbon-source-dependent volatile profiles were generated during ASD (Hewavitharana et al. 2014). In the current study, significant differences in the ability to suppress $R$. solani AG-5 were observed among ASD treatments that utilized different carbon substrates. We hypothesize that the differential effect of carbon amendments is at least partially due to unique
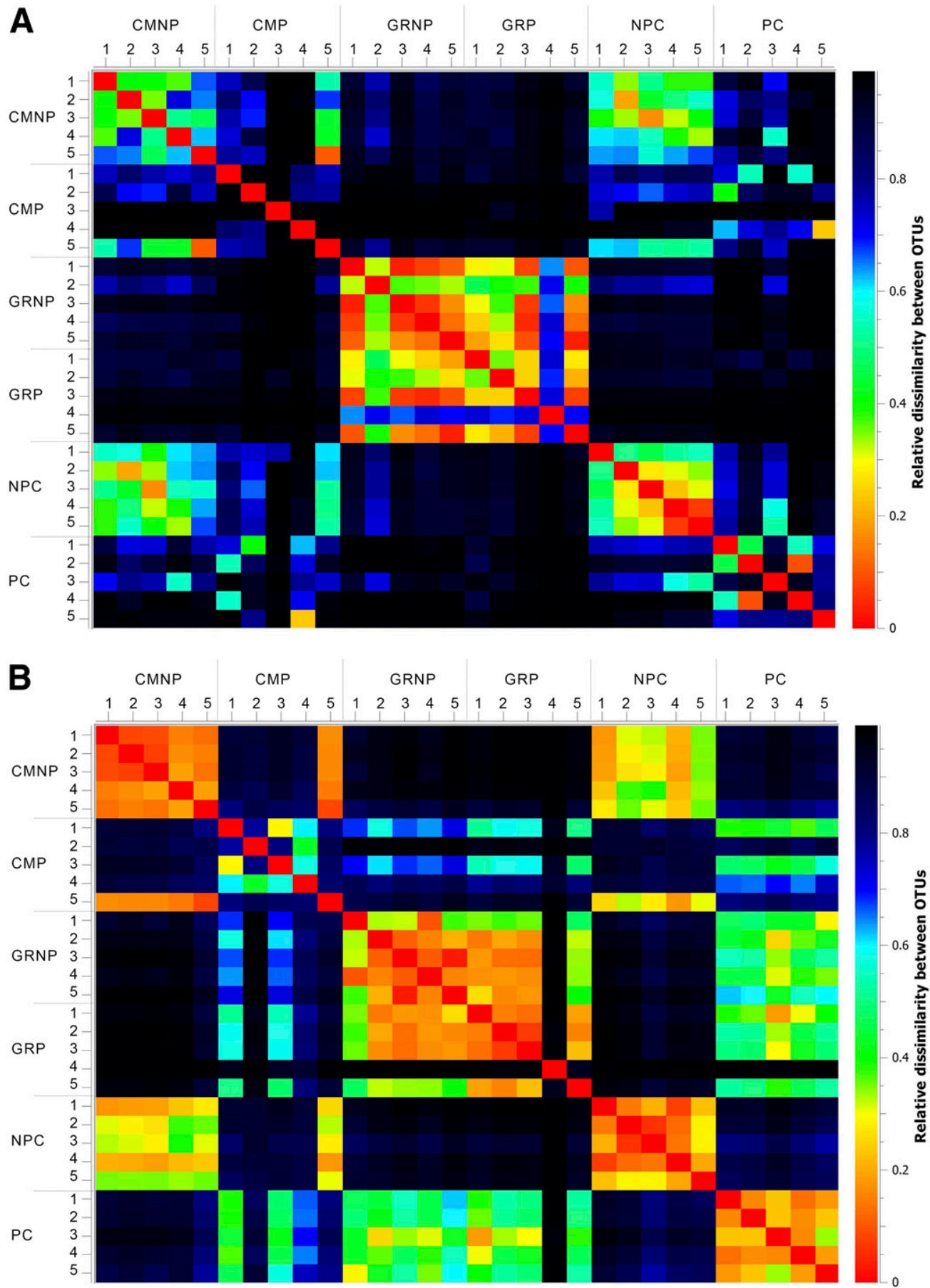

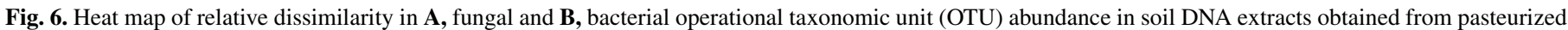

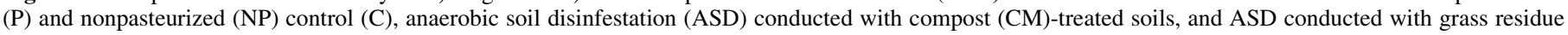

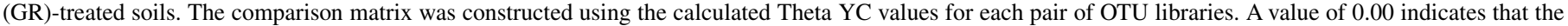
two groups are identical. 
chemistries generated and associated biological changes that occurred in the soil system during and after ASD.

Among the carbon inputs examined, use of GR in the conduct of ASD provided the most consistent improvement in apple seedling growth and pathogen suppression. The effect of GR input rate used on efficacy of ASD was pathogen dependent. Suppression of $R$. solani AG-5 was attained during ASD regardless of GR input rate and, in one experiment, disease control was observed in response to ASD even in the absence of a carbon input. In contrast, ASD efficacy for control of $P$. penetrans was influenced by the rate of GR input, with optimal nematode suppression requiring an input rate of 10 to $20 \mathrm{tha}^{-1}$. Lesion nematode is a consistent component of the apple replant disease pathogen complex and is associated with elevated disease severity (Mazzola and Manici 2012); therefore, the GR input rate of $20 \mathrm{tha}^{-1}$ is likely to be required for effective disease control.

Application of SM in ASD effectively reduced pathogen inoculum persistence in soil, improved apple seedling growth parameters, and reduced root infection by $R$. solani AG-5. This observation may be attributed to the activity of antifungal volatile compounds released upon hydrolysis of glucosinolates, including allyl isothiocyanate (Mazzola et al. 2007). However, previous analysis of the volatiles generated during the anaerobic phase of ASD demonstrated additional potentially active volatiles, including organic sulfur compounds such as dimethyl sulfide, carbon disulfide, dimethyl disulfide, and dimethyl trisulfide, that are produced when ASD is conducted using SM (Hewavitharana et al. 2014). These same sulfide compounds were produced when ASD was conducted using GR as the carbon input (Hewavitharana et al. 2014). Some of these sulfide compounds such as dimethyl trisulfide have been reported to have antifungal (Fernando et al. 2005), antioomycete (De Vrieze et al. 2015), and nematicidal (Cabrera et al. 2010) activity. In vitro assays demonstrated that dimethyl trisulfide was effective in suppressing hyphal growth of $R$. solani AG-5 at a minimum concentration of $7.843 \mathrm{mg}$ a.i./liter (Hewavitharana et al. 2014). Volatiles produced during ASD conducted with ET effectively controlled soilborne pathogens of apple (Hewavitharana et al. 2014). Significantly higher seedling root infection in the pasteurized soil relative to the nonpasteurized soil would be due to loss of general suppression in the pasteurized soil toward the pathogen, which is an established phenomenon in natural soil (Mazzola 2002).

Compositional changes to the soil microbiome during ASD were evaluated initially by conducting T-RFLP analysis of the total soil fungal DNA after the anaerobic phase of incubation. One each of the most effective (GR) and least effective (CM) amendments was

TABLE 5. Attributes of soil fungal community diversity upon completion of the anaerobic soil disinfestation based upon relative abundance of operational taxonomic units (OTU) ${ }^{\mathrm{y}}$

\begin{tabular}{|c|c|c|c|c|}
\hline Treatment $^{\mathrm{z}}$ & $\begin{array}{l}\text { Sequences } \\
\text { per sample }\end{array}$ & $\begin{array}{l}\text { Average number of } \\
\text { OTU }(97 \%) \text { per sample }\end{array}$ & Chao1 & Shannon $\mathrm{H}$ \\
\hline NPC & 71,659 & $140 \pm 7$ & $163 \pm 9$ & $4.22 \pm 0.15$ \\
\hline $\mathrm{PC}$ & 73,595 & $36 \pm 6$ & $44 \pm 10$ & $1.75 \pm 0.29$ \\
\hline CMNP & 71,263 & $151 \pm 14$ & $174 \pm 20$ & $4.35 \pm 0.34$ \\
\hline CMP & 42,870 & $59 \pm 49$ & $67 \pm 59$ & $2.16 \pm 1.14$ \\
\hline GRNP & 151,739 & $54 \pm 6$ & $71 \pm 8$ & $2.30 \pm 0.26$ \\
\hline GRP & 151,473 & $54 \pm 8$ & $70 \pm 7$ & $2.66 \pm 0.41$ \\
\hline
\end{tabular}

y Data are presented as mean \pm standard deviation, $n=5$. OTU are defined as sequences sharing $>97 \%$ similarity.

z Treatments: Pasteurized (P) and nonpasteurized (NP) soil was amended with composted steer manure (CM, $10.08 \mathrm{tha}^{-1}$ ) or orchard grass (GR, $20 \mathrm{t} \mathrm{ha}^{-1}$ ). Controls (NPC and PC) received no carbon input.

TABLE 6. Attributes of soil bacterial community diversity upon completion of the anaerobic soil disinfestation (ASD) period based upon relative abundance of operational taxonomic units (OTU) ${ }^{\mathrm{y}}$

\begin{tabular}{lcccc}
\hline Treatment $^{z}$ & $\begin{array}{c}\text { Sequences } \\
\text { per sample }\end{array}$ & $\begin{array}{c}\text { Average number of } \\
\text { OTU (97\%) per sample }\end{array}$ & Chao1 & Shannon H \\
\hline NPC & 31,917 & $442 \pm 15$ & $532 \pm 27$ & $6.84 \pm 0.02$ \\
PC & 31,983 & $250 \pm 17$ & $293 \pm 23$ & $5.45 \pm 0.22$ \\
CMNP & 25,446 & $413 \pm 46$ & $477 \pm 80$ & $6.86 \pm 0.13$ \\
CMP & 26,958 & $356 \pm 48$ & $428 \pm 69$ & $6.18 \pm 0.46$ \\
GRNP & 40,129 & $245 \pm 15$ & $307 \pm 24$ & $3.96 \pm 0.44$ \\
GRP & 34,298 & $193 \pm 30$ & $236 \pm 39$ & $4.14 \pm 0.43$ \\
\hline
\end{tabular}

y Data are presented as mean \pm standard deviation, $n=5$. OTU are defined as sequences sharing $>97 \%$ similarity.

z Treatments: Pasteurized (P) and nonpasteurized (NP) soil was amended with composted steer manure (CM, $10.08 \mathrm{t} \mathrm{ha}^{-1}$ ) or orchard grass (GR, $20 \mathrm{t} \mathrm{ha}^{-1}$ ) in the conduct of ASD. The control $(\mathrm{C})$ received no carbon input.

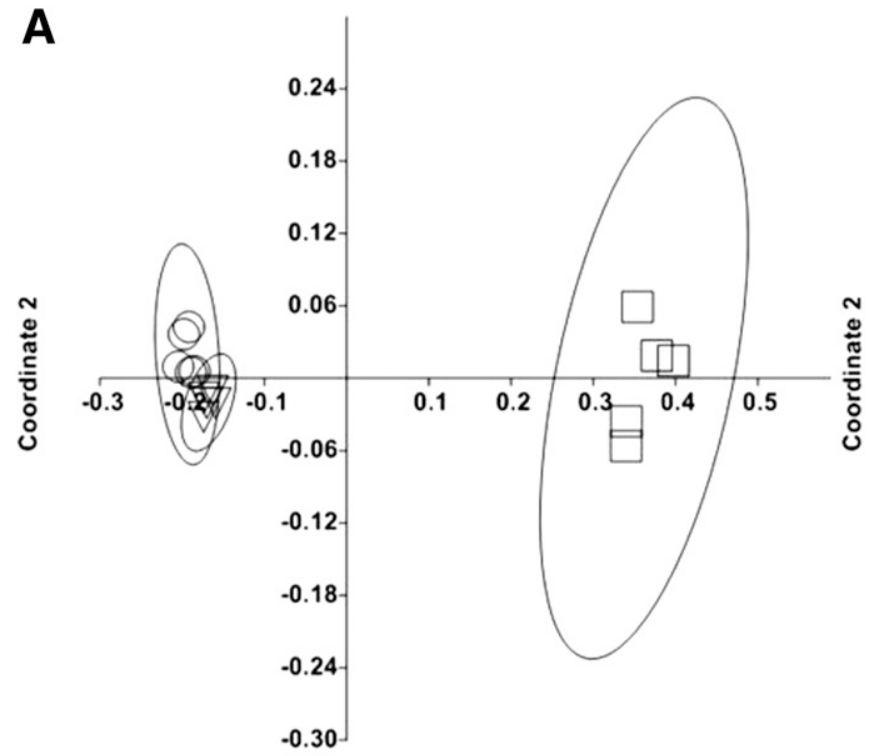

Coordinate 1

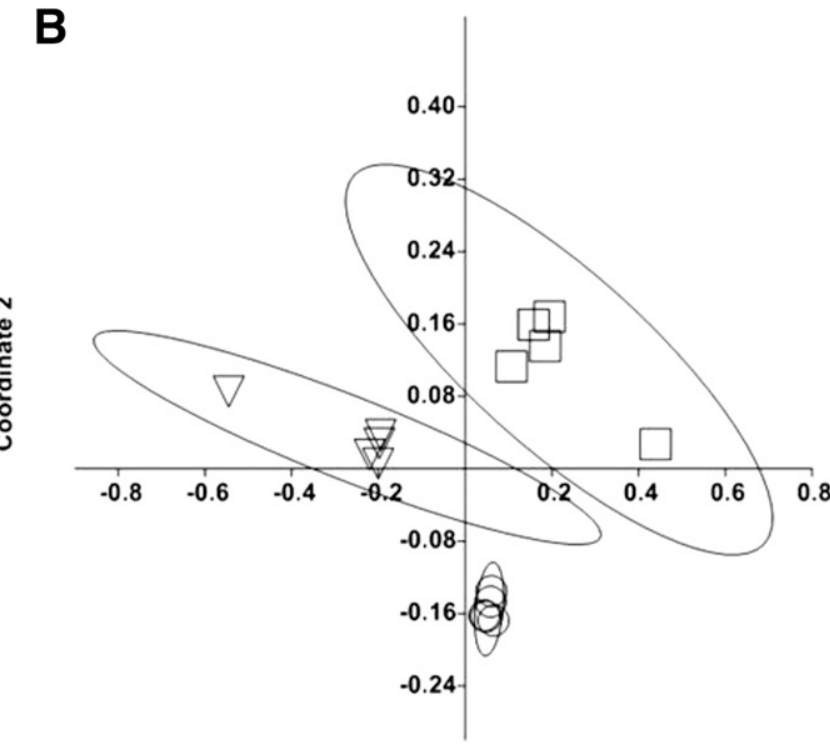

Coordinate 1

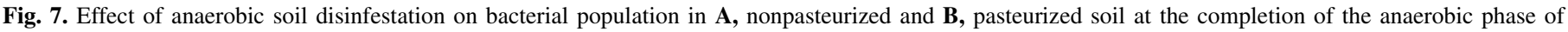

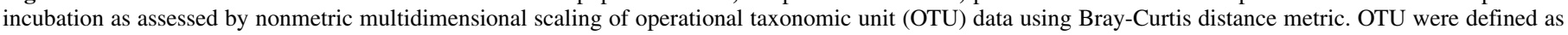

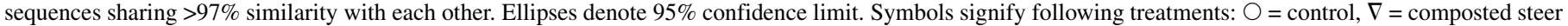
manure, and $\square=$ orchard grass. 
chosen to characterize their relative effects on composition of this community. ASD conducted on pasteurized soil with CM appeared to have minimal effect on the fungal community because the population was highly similar to the PC. These two treatments grouped with the nonpasteurized control, whereas the nonpasteurized ASD-CM treatment stands alone. Interestingly, the fungal communities from the pasteurized and nonpasteurized GR treatments were more similar to each other and dissimilar from all other treatments. Supporting the findings of T-RFLP analysis, non-metric multidimensional scaling plots derived from Illumina sequence data suggested that fungal populations in GRNP and GRP treatments were more similar to each other than that in other soil treatments. In this instance, it appears that the GR but not CM ASD treatment possessed the capacity to transform fungal populations to that attained in the nonpasteurized ASD-GR treatment through its transfer of microbial inoculum to the pasteurized soil system. The inability of the ASD$\mathrm{CM}$ treatment to confer a similar response could result from prior exhaustion of carbon-based resources contained by the compost. Furthermore, CM may consist of a microbial community which is unsuccessful in competing with resident soil microbiome. The lack of available substrate needed for microbial colonization would thereby decrease suppressiveness against competitive saprophytic pathogens such as $R$. solani that can consume substrates rich in cellulose (Boehm et al. 1997). This hypothesis is further supported by the observation that no significant effect of soil pasteurization, prior to ASD, was observed on most of the parameters evaluated for disease suppression and seedling growth for ASD-CM treatment. Observation of lower $\mathrm{pH}$ values in nonpasteurized treatments relative to pasteurized treatments indicates that resident biology contributes to the generation of acidic products in soil during the anaerobic phase of incubation. Overall, although chemistries play a major role in disease control conferred by ASD, initial soil biology may not be as important as the changes exerted on the soil system through introduction of microbiology associated with the soil amendment itself and its transformation through ASD.

As would be expected, pasteurized soils possessed reduced fungal and bacterial diversities relative to nonpasteurized soil, with the exception of ASD-GR-treated soils. In general, nonsuppressive ASD-CM-treated soil possessed a microbiome that was more diverse than the ASD-GR soil, which was suppressive to $R$. solani AG-5. Such a correspondence between a reduction in overall diversity of the rhizosphere microbiome and enhanced disease suppression was previously observed in Brassicaceae SM-amended soils (Mazzola et al. 2015). Fungal and bacterial communities recovered from the rhizosphere of apple were less diverse than those from nontreated or fumigated soils. However, the microbiome possessed by the SM treatment included amplification of several fungal and bacterial groups demonstrated to possess activity toward fungal and nematode plant parasites (Mazzola et al. 2015). This community demonstrated an enhanced capacity to limit recolonization of orchard soils by apple root pathogens, including $P$. penetrans and Pythium spp.

Acidobacteria, Actinobacteria, Chlorofexi, and Plactomycetes taxa were more abundant in the control and ASD-CM treatments. Compared with GR treatment with higher organic matter content, the control and CM treatments should possess high amounts of recalcitrant organic matter. For instance, total N content was $2.19 \%$ and $\mathrm{C}: \mathrm{N}$ ratio was 19:1 in GR tissue whereas total $\mathrm{N}$ content was 1.35\% and C:N ratio was 11:1 in CM. According to the copiotroph/ oligotrophy hypothesis (Fierer et al. 2007), higher densities of oligotrophic prokaryotes may be found in bogs and soils with higher composition of recalcitrant organic matter (Dion and Nautiyal 2008). Members of both $\beta$-Proteobacteria and Bacteroidetes, which have copiotrophic attributes (Fierer et al. 2007), were abundant in the PC treatment. This could be due to release of available nutrients in the soil caused by turnover of soil microorganisms upon pasteurization. This observation agrees with Padmanabhan et al. (2003), who report that active members of these two phyla were some of the initial metabolizers of labile carbon inputs. Abundance of $\gamma$-Proteobacteria was amplified in GR amendment treatments, regardless of soil pasteurization. This trend relatively follows Cleveland et al. (2007), who observed organisms within $\gamma$-Proteobacteria increase in abundance in response to addition of dissolved organic matter leached from native plant litter compared with the water control, although this study was conducted under aerobic conditions.

The suppressive ASD-GR treatments possessed elevated abundance of fungal and bacterial OTU that were previously reported to have traits that functioned in suppression of plant pathogens. For example, the coprophilous fungus $C$. areolate, which was more abundant in the ASD-GR-treated soils, has been reported to produce Cercophorins $\mathrm{A}$ to $\mathrm{C}$, which are antifungal and cytotoxic metabolites (Whyte et al. 1996). Similarly, Paenibacillus spp. were more abundant in the ASD-GR treatment and were shown to produce multiple volatiles that demonstrate antagonistic activity against soilborne plant pathogens, including $R$. solani (Liu et al. 2008; Rybakova et al. in press). These findings indicated that amplification of specific functional groups in response to ASD is likely to contribute to the overall level of disease control achieved, and these groups may have the potential to serve as biological reference points to predict disease control efficacy. The finding that disease suppression was attained in an ASD system that exhibited less diversity of the microbiome than a nonsuppressive ASD system further suggests that system efficacy is dependent upon specific functional groups rather than enhanced system diversity.

The preponderance of studies concerning the implementation of anaerobic soil disinfestation have been formulated with the notion that chemical or physical mechanisms of action are dominant determinants of the disease control outcome (Blok et al. 2000). Although chemical mechanisms of action may contribute to pathogen suppression in response to either of these control strategies, an emerging body of evidence, including the current studies, either suggests or explicitly demonstrates the role of biological factors participating in the process. The mechanisms functional in pathogen suppression may differ with the target pathogen and may also differ in a temporal manner (Momma et al. 2013). An understanding of these processes is integral to the effective utilization of ASD, alone or in combination with other measures, across the diversity of individual and complexes of pathogens encountered in orchard production systems. For example, sequence of application when integrating treatments may inadvertently result in altered action or elimination of biological entities contributing to disease control. Our understanding of disease control processes attained through the use of biologically active inputs such as ASD will enable effective management of differing modes of action, yielding an enhanced spectrum of pathogen control. Such a capacity is necessary to ensure the commercially required levels of soilborne disease control previously achieved through preplant soil fumigation.

\section{ACKNOWLEDGMENTS}

This work was supported, in part, through the USDA National Institute of Food and Agriculture competitive grants program. We thank M. F. Cohen and C. Reardon for critical review of the manuscript prior to submission.

\section{LITERATURE CITED}

Atsushi, T., Ryuji, F., and Hirotada, K. 1975. Antibiotic sporacuracin production. Japan Patent 75,125,094.

Atta, H. M. 2015. Biochemical studies on antibiotic production from Streptomyces sp.: Taxonomy, fermentation, isolation and biological properties. J. Saudi Chem. Soc. 19:12-22.

Blok, W. M., Lamers, J. G., Termorshuizen, A. J., and Bollen, G. J. 2000. Control of soilborne plant pathogens by incorporating fresh organic amendments followed by tarping. Phytopathology 90:253-259. 
Boehm, M. J., Wu, T., Stone, A. G., Kraakman, B., Iannotti, D. A., Wilson, G. E., Madden, L. V., and Hoitink, H. A. J. 1997. Cross-polarized magicangle spinning (sup13)C nuclear magnetic resonance spectroscopic characterization of soil organic matter relative to culturable bacterial species composition and sustained biological control of Pythium root rot. Appl. Environ. Microbiol. 63:162-168.

Bonanomi, G., Antignani, V., Pane, C., and Scala, F. 2007. Suppression of soilborne fungal diseases with organic amendments. J. Plant Pathol. 89: 311-324.

Boonsang, N., Dethoup, T., Singburaudom, N., Gomes, N. G. M., and Kijjoa, A. 2014. In vitro antifungal activity screening of crude extracts of soil fungi against plant pathogenic fungi. J. Biopestic. 7:156-166.

Burr, T. J., Hunter, J. E., Ogawa, J. M., and Abawi, G. S. 1978. A root rot of apple caused by Rhizoctonia solani in New York nurseries. Plant Dis. Rep. 62:476-479.

Butler, D., Kokalis-Burelle, N., Muramoto, J., Shennan, C., McCollum, T. G., and Rosskopf, E. N. 2012a. Impact of anaerobic soil disinfestation combined with soil solarization on plant-parasitic nematodes and introduced inoculum of soilborne plant pathogens in raised-bed vegetable production. Crop Prot. 39:33-40.

Butler, D. M., Rosskopf, E. N., Kokalis-Burelle, N., Albano, J. P., Muramoto, J., and Shennan, C. 2012b. Exploring warm-season cover crops as carbon sources for anaerobic soil disinfestation (ASD). Plant Soil 355:149-165.

Cabrera, J. A., Gan, J., Hanson, B. D., and Wang, D. 2010. Factors affecting the nematicidal activity of dimethyl disulfide. Pages 5.1-5.2 in: Proc. Proc. Annu. Int. Res. Conf. Methyl Bromide Altern. Emiss. Reduct. MBAO, Fresno, CA.

Caporaso, J. G., Lauber, C. L., Walters, W. A., Berg-Lyons, D., Lozupone, C. A., Turnbaugh, P. J., Fierer, N., and Knight, R. 2011. Global patterns of $16 \mathrm{~S}$ rRNA diversity at a depth of millions of sequences per sample. Proc. Natl. Acad. Sci. USA 108:4516-4522.

Chao, A. 1984. Non-parametric estimation of the number of classes in a population. Scand. J. Stat. 11:265-270.

Chung, Y., Cheng, C., Chen, T., Hsu, J., and Kui, C. 2010. Structure of the bacterial community in a biofilter during dimethyl sulfide (DMS) removal processes. Bioresour. Technol. 101:7165-7168.

Cleveland, C. C., Nemergut, D. R., Schmidt, S. K., and Townsend, A. R. 2007. Increases in soil respiration following labile carbon additions linked to rapid shifts in soil microbial community composition. Biogeochemistry 82 : 229-240.

Coronelli, C., Bardone, M. R., and Pagani, H. 1975. Antibiotic activities from Streptosporangium vulgare ATCC 21096. US Patent 3,899,396.

De Vrieze, M., Pandey, P., Bucheli, T. D., Varadarajan, A. R., Ahrens, C. H., Weisskopf, L., and Bailly, A. 2015. Volatile organic compounds from native potato-associated Pseudomonas as potential anti-oomycete agents. Front. Microbiol. 6:1295.

Dion, P., and Nautiyal, C. S., eds. 2008. Microbiology of Extreme Soils. Springer-Verlag, Berlin, Heidelberg.

Fernando, W. G. D., Ramarathnam, R., Krishnamoorthy, A. S., and Savchuk, S. C. 2005. Identification and use of potential bacterial organic antifungal volatiles in biocontrol. Soil Biol. Biochem. 37:955-964.

Fierer, N., Bradford, M. A., and Jackson, R. B. 2007. Toward an ecological classification of soil bacteria. Ecology 88:1354-1364.

Finkmann, W., Altendorf, K., Stackebrandt, E., and Lipski, A. 2000. Characterization of $\mathrm{N}_{2} \mathrm{O}$-producing Xanthomonas-like isolates from biofilters as Stenotrophomonas nitritireducens sp. nov., Luteimonas mephitis gen. nov., sp. nov. and Pseudoxanthomonas broegbernensis gen. nov., sp. nov. Int. J. Syst. Evol. Microbiol. 50:273-282.

Forge, T., Neilsen, G., Neilsen, D., Hogue, E., and Faubion, D. 2013. Composted dairy manure and alfalfa hay mulch affect soil ecology and early production of 'Braeburn' apple on M.9 rootstock. HortScience 48:645-651.

Gardes, M., and Bruns, T. D. 1993. ITS primers with enhanced specificity for basidiomycetes - application to the identification of mycorrhizae and rusts. Mol. Ecol. 2:113-118

Granatstein, D., and Dauer, P. 2000. Trends in organic tree fruit production in Washington State. CSANR Rep. No. 1. Washington State University, Wenatchee.

Grantina-Ievina, L., Andersone, U., Berkolde, D., Nikolajeva, V., and Ievinsh, G. 2013. Critical tests for determination of microbial quality and biological activity in commercial vermicompost samples of different origins. Appl. Microbiol. Biotechnol. 97:10541-10554.

Hammer, Ø., Harper, D. A. T., and Ryan, P. D. 2001. PAST: Paleontological statistics software package for education and data analysis. Paleontol. Electron. 4:1-9.

Handiseni, M., Brown, J., Zemetra, R., and Mazzola, M. 2013. Effect of Brassicaceae seed meals with different glucosinolate profiles on Rhizoctonia root rot of wheat. Crop Prot. 48:1-5.

Helliker, P. E. 2002. California management plan: 1,3-Dicholorpropene. California Department of Pesticide Regulation, Sacramento.
Hewavitharana, S. S., Rudell, D., and Mazzola, M. 2014. Carbon sourcedependent antifungal and nematicidal volatiles derived during anaerobic soil disinfestation. Eur. J. Plant Pathol. 140:39-52.

Isutsa, D., and Merwin, I. 2000. Malus germplasm varies in resistance or tolerance to apple replant disease in a mixture of New York orchard soils. HortScience 35:262-268.

Lazarovits, G. 2001. Management of soil-borne plant pathogens with organic soil amendments: A disease control strategy salvaged from the past. Can. J. Plant Pathol. 23:1-7.

Liu, W.-W., Mu, W., Zhu, B.-Y., Du, Y.-C., and Liu, F. 2008. Antagonistic activities of volatiles from four strains of Bacillus spp. and Paenibacillus spp. against soil-borne plant pathogens. Agric. Sci. China 7:1104-1114.

Mai, W. F., and Abawi, G. S. 1981. Controlling replant diseases of pome and stone fruit in northeastern United States by preplant fumigation. Plant Dis. 65:859-864.

Mapperson, R. R., Kotiw, M., Davis, R. A., and Dearnaley, J. D. W. 2014. The diversity and antimicrobial activity of Preussia sp. endophytes isolates from Australian dry rainforests. Curr. Microbiol. 68:30-37.

Mazzola, M. 1997. Identification and pathogenicity of Rhizoctonia spp. isolated from apple roots and orchard soils. Phytopathology 87:582-587.

Mazzola, M. 1998. Elucidation of the microbial complex having a causal role in the development of apple replant disease in Washington. Phytopathology 88:930-38.

Mazzola, M. 2002. Mechanisms of natural soil suppressiveness to soilborne diseases. Antonie Leeuwenhoek 81:557-564.

Mazzola, M., Brown, J., Izzo, A. D., and Cohen, M. F. 2007. Mechanism of action and efficacy of seed meal-induced pathogen suppression differ in a Brassicaceae species and time-dependent manner. Phytopathology 97: 454-460.

Mazzola, M., Brown, J., Zhao, X., Izzo, A. D., and Fazio, G. 2009. Interaction of brassicaceous seedmeal and apple rootstock on recovery of Pythium spp. and Pratylenchus penetrans from roots grown in replant soils. Plant Dis. 93: 51-57.

Mazzola, M., Hewavitharana, S. S., and Strauss, S. L. 2015. Brassica seed meal soil amendments transform the rhizosphere microbiome and improve apple production though resistance to pathogen reinfestation. Phytopathology 105:460-469.

Mazzola, M., and Manici, L. 2012. Apple replant disease: Role of microbial ecology in cause and control. Annu. Rev. Phytopathol. 50:45-65.

Mazzola, M., and Mullinix, K. 2005. Comparative field efficacy of management strategies containing Brassica napus seed meal or green manure for the control of apple replant disease. Plant Dis. 89:1207-1213.

Mazzola, M., and Zhao, X. 2010. Brassica juncea seed meal particle size influences chemistry but not soil biology-based suppression in individual agents inciting apple replant disease. Plant Soil 337:313-324.

McCarty, D. G., II, Inwood, A. E. E., Ownley, B. H., Sams, C. E., Wszelaki, A. L., and Butler, D. M. 2014. Field evaluation of carbon sources for anaerobic soil disinfestation in tomato and bell pepper production in Tennessee. HortScience 49:272-280.

Momma, N., Kobara, Y., Uematsu, S., Kita, N., and Shinmura, A. 2013. Development of biological soil disinfestations in Japan. Appl. Microbiol. Biotechnol. 97:3801-3809.

Momma, N., Momma, M., and Kobara, Y. 2010. Biological soil disinfestation using ethanol: Effect on Fusarium oxysporum f. sp. lycopersici and soil microorganisms. J. Gen. Plant Pathol. 76:336-344.

Muramoto, J., Shennan, C., Zavatta, M., Toyama, L., Hewavitharana, S. S., and Mazzola, M. 2015. Controlling Fusarium wilt of strawberries by anaerobic soil disinfestation. Pages 16.1-16.4 in: Proc. Annu. Int. Res. Conf. Methyl Bromide Altern. Emiss. Reduct. MBAO, Fresno, CA.

Nakasaki, K., Saito, M., and Suzuki, N. 2007. Coprinellus curtus (Hitoyotake) prevents diseases of vegetables caused by pathogenic fungi. FEMS Microbiol. Lett. 275:286-291.

Padmanabhan, P., Padmanabhan, S., DeRito, C., Gray, A., Gannon, D., Snape, J. R., Tsai, C. S., Park, W., Jeon, C., and Madsen, E. L. 2003. Respiration of 13C-labelled substrates added to soil in the field and subsequent 16S rRNA gene analysis of 13C-labelled soil DNA. Appl. Environ. Microbiol. 69: 1614-1622.

Ponnamperuma, F. N. 1972. The chemistry of submerged soils. Adv. Agron. 24:29-96.

Robertson, C. E., Harris, J. K., Wagner, B. D., Granger, D., Browne, K., Tatem, B., Feazel, L. M., Park, K., Pace, N. R., and Frank, D. N. 2013. Explicet: Graphical user interface software for metadata-driven management, analysis and visualization of microbiome data. Bioinformatics 29:3100-3101.

Rybakova, D., Cernava, T., Köberl, M., Liebminger, S., Etemadi, M., and Berg, G. Endophytes-assisted biocontrol: Novel insights in ecology and the mode of action of Paenibacillus. Plant Soil In press. doi:10.1007/s11104015-2526-1

Shennan, C., Muramoto, J., Lamers, J., Mazzola, M., Rosskopf, E. N., Kokalis-Burelle, N., Momma, N., Butler, D. M., and Kobara, Y. 2014. 
Anaerobic soil disinfestation for soil borne disease control in strawberry and vegetable systems: Current knowledge and future directions. Acta Hortic. 1044:165-175.

St. Laurent, A., Merwin, I. A., and Thies, J. E. 2008. Long-term orchard groundcover management systems affect soil microbial communities and apple replant disease severity. Plant Soil 304:209-225.

Supaphon, P., Phongpaichit, S., Rukachaisirikul, V., and Sakayaroj, J. 2013. Antimicrobial potential of endophytic fungi derived from three seagrass species: Cymodocea serrulata, Halophila ovalis and Thalassia hemprichii. PLoS One 8:e72520.

Tilston, E., Pitt, D., and Groenhof, A. C. 2002. Composted recycled organic matter suppresses soil-borne diseases of field crops. New Phytol. 154:731-740.

UNEP. 1987. The Montreal Protocol on substances that deplete the ozone layer. Online publication. http://ozone.unep.org/en/handbook-montreal-protocolsubstances-deplete-ozone-layer/5

Wagner, B. D., Roberson, C. E., and Harris, J. K. 2011. Application of two-part statistic for comparison of sequence variant counts. PLoS One 6:e20296.
Wani, S. A., Chand, S., and Ali, T. 2013. Potential use of Azotobacter chroococcum in crop production: An overview. Curr. Agric. Res. J. 1: 35-38.

Weerakoon, D. M. N., Reardon, C. L., Paulitz, T. C., Izzo, A. D., and Mazzola, M. 2012. Long-term suppression of Pythium abappressorium induced by Brassica juncea seed meal amendment is biologically mediated. Soil Biol. Biochem. 51:44-52.

White, T., Bruns, T., Lee, S., and Taylor, J. 1990. Amplification and direct sequencing of fungal ribosomal RNA genes for phylogenetics. Pages 315-322 in: PCR Protocols: A Guide to Methods and Applications. M. A. Innis, D. Gelfand, J. Sninsky, and T. White, eds. Academic Press, San Diego, CA.

Whyte, A. C., Gloer, J. B., Scott, J. A., and Malloch, D. 1996. Cercophorins A-C: Novel antifungal and cytotoxic metabolites from the coprophilous fungus Cercophora areolata. J. Nat. Prod. 59:765-769.

Yue, J. C., and Clayton, M. K. 2005. A similarity measure based on species proportions. Commun. Stat. Theor. M. 34:2123-2131. 